\title{
Segurança do bit menos significativo no RSA e em curvas elípticas
}

\author{
Dionathan Nakamura \\ DissertaÇÃo APRESEntada \\ $\mathrm{AO}$ \\ Instituto De Matemática e Estatística \\ DA \\ Universidade de SÃo PaUlo \\ PARA \\ OBTENÇÃ̃ DO TÍTULO \\ $\mathrm{DE}$ \\ Mestre em CiênCIAS \\ Programa: Ciência da Computação \\ Orientador: Prof. Dr. Routo Terada \\ Durante o desenvolvimento deste trabalho o autor \\ recebeu auxílio financeiro da CAPES
}

São Paulo, dezembro de 2011 



\title{
Segurança do bit menos significativo no RSA e em curvas elípticas
}

\author{
Esta dissertação contém as correções e alterações \\ sugeridas pela Comissão Julgadora durante a defesa \\ realizada por Dionathan Nakamura em 16 de dezembro de 2011. \\ O original encontra-se disponível no Instituto de \\ Matemática e Estatística da Universidade de São Paulo.
}

Comissão Julgadora:

- Prof. Dr. Routo Terada (orientador) - IME-USP

- Prof. Dr. Paulo Sérgio Licciardi Messeder Barreto - EP-USP

- Prof. Dr. Julio César López Hernández - IC-UNICAMP 


\section{Agradecimentos}

Agradeço ao Prof. Routo Terada pela orientação, aos colegas do laboratório de segurança da dados, em especial à Denise pelos conselhos gerais, à CAPES pelo suporte financeiro, aos colegas de pós-graduação da matemática pela ajuda em álgebra abstrata, ao Prof. Nélson Tanaka pela ajuda em estatística e finalmente a minha mãe Keiko que incentivou toda esta jornada. 


\section{Resumo}

Sistemas criptográficos como o RSA e o Diffie-Hellman sobre Curvas Elípticas (DHCE) têm fundamento em problemas computacionais considerados difíceis, por exemplo, o problema do logaritmo (PLD) e o problema da fatoração de inteiros (PFI). Diversos trabalhos têm relacionado a segurança desses sistemas com os problemas subjacentes. Também é investigada a segurança do LSB (bit menos significativo) da chave secreta no DHCE (no RSA é o LSB da mensagem) com relação à segurança de toda a chave. Nesses trabalhos são apresentados algoritmos que conseguem inverter os sistemas criptográficos citados fazendo uso de oráculos que predizem o LSB. Nesta dissertação, fazemos a implementação de dois desses algoritmos. Identificamos parâmetros críticos e mudamos a amostragem do formato original. Com essa mudança na amostragem conseguimos uma melhora significativa nos tempos de execução. Um dos algoritmos (ACGS), para valores práticos do RSA, era mais lento que a solução para o PFI, com nosso resultado passou a ser mais veloz. Ainda, mostramos como provas teóricas podem não definir de maneira precisa o tempo de execução de um algoritmo.

Palavras-chave: Criptografia, RSA, Diffie-Hellman, Curvas Elípticas. 


\section{Abstract}

Cryptographic systems like RSA and Elliptic Curve Diffie-Hellman (DHCE) is based on computational problems that are considered hard, e.g. the discrete logarithm (PLD) and integer factorization (PFI) problems. Many papers investigated the relationship between the security of these systems to the computational difficulty of the underlying problems. Moreover, they relate the bit security, actually the LSB (Least Significant Bit), of the secret key in the DHCE and the LSB of the message in the RSA, to the security of the whole key. In these papers, algorithms are presented to invert these cryptographic systems making use of oracles that predict the LSB. In this dissertation we implement two of them. Critical parameters are identified and the original sampling is changed. With the modified sampling we achieve an improvement in the execution times. For practical values of the RSA, the algorithm ACGS becomes faster than the PFI. Moreover, we show how theoretical proofs may lead to inaccurate timing estimates.

Keywords: Cryptography, RSA, Diffie-Hellman, Elliptic Curves. 


\section{Sumário}

Agradecimentos

Resumo v v

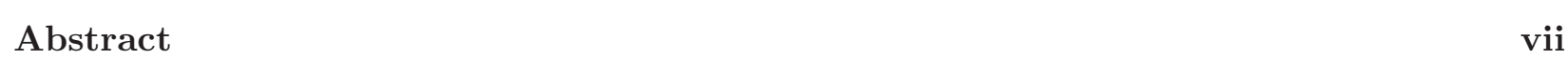

Lista de Figuras 2 xi

Lista de Tabelas $\quad$ xiii

Lista de Algoritmos $\quad$ XV

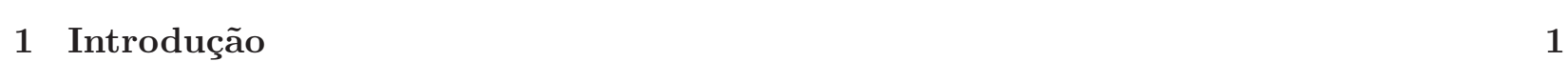

1.1 Trabalhos relacionados . . . . . . . . . . . . . . . . . . . . 2

1.2 Objetivos e motivação $\ldots \ldots \ldots \ldots \ldots \ldots \ldots$

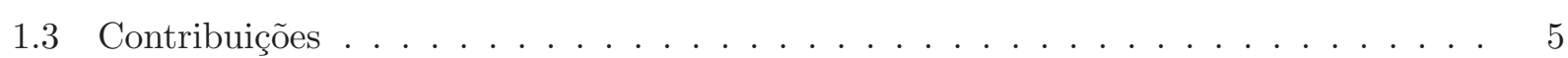

1.4 Organização do trabalho $\ldots \ldots \ldots \ldots \ldots \ldots$

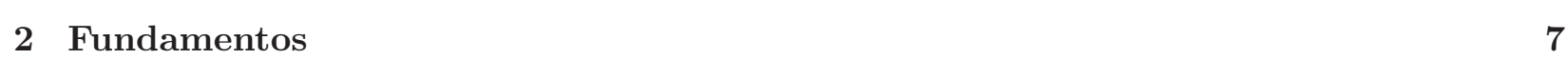

2.1 Álgebra abstrata . . . . . . . . . . . . . . . . . . . . . . 7

2.2 Curvas elípticas $\ldots \ldots \ldots \ldots \ldots \ldots \ldots$

2.3 Problemas difíceis e notação assintótica $\ldots \ldots \ldots \ldots$. . . . . . . . . . . . 13

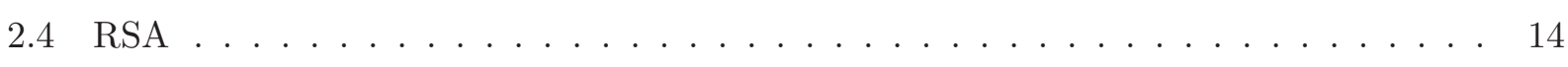

2.5 Diffie-Hellman sobre curvas elípticas . . . . . . . . . . . . . . . . . 15

2.6 Tamanho das chaves . . . . . . . . . . . . . . . . . . . . . . 17

2.7 Números pseudoaleatórios $\ldots \ldots \ldots \ldots \ldots \ldots \ldots$

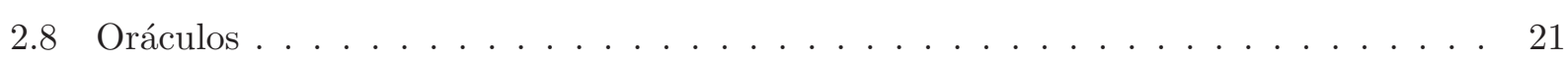

2.9 Máximo divisor comum . . . . . . . . . . . . . . . . . . 22

2.10 Desigualdade de Chebyshev . . . . . . . . . . . . . . . . . . 23 


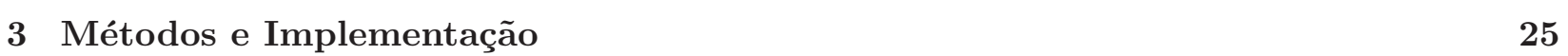

3.1 Algoritmos para o RSA . . . . . . . . . . . . . . . . . 25

3.1 .1 Sobre o algoritmo FS para o RSA . . . . . . . . . . . . . . . 32

3.2 Algoritmos para o DHCE . . . . . . . . . . . . . . . . . 33

3.2 .1 Sobre o algoritmo JV para o DHCE em isogenias . . . . . . . . . . . . . 35

3.3 Biblioteca criptográfica Relid . . . . . . . . . . . . . . 37

$4 \quad$ Resultados $\quad 39$

4.1 Resultados para o algoritmo ACGS . . . . . . . . . . . . . . . . . . . 39

4.1 .1 Tempos do modelo original _. . . . . . . . . . . . . . . . 39

4.1 .2 Diminuindo o número de amostras . . . . . . . . . . . . . . . . . 43

4.1 .3 Reducão no limitante do BKGCD . . . . . . . . . . . . . . . . . . 45

4.1 .4 Inferência de tempos para o RSA . . . . . . . . . . . . . . . . 46

4.2 Resultados para o algoritmo BS . . . . . . . . . . . . . . . . . . 48

4.2 .1 Tempos sem o uso do oráculo B . . . . . . . . . . . . . . . . 48

4.2 .2 Tempos usando o oráculo B . . . . . . . . . . . . . . . 50

4.3 Tempos para o algoritmo JV . . . . . . . . . . . . . . . . . 52

5 Conclusões

Referências 


\section{Lista de Figuras}

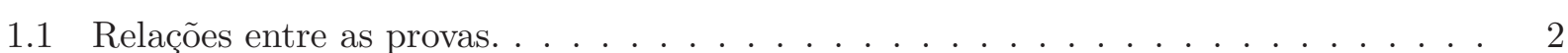

1.2 Relacões entre as provas e o oráculo . . . . . . . . . . . . . . . . . . . 4

$2.1 \quad$ Curva elíptica $y^{2}=x^{3}-7 x \ldots \ldots \ldots \ldots \ldots \ldots \ldots$

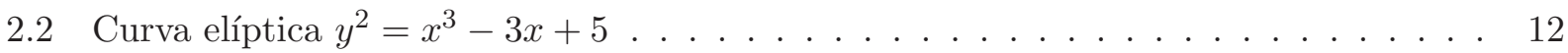

4.1 Tempo consumido em relação ao número de amostras . . . . . . . . . . . . . . . 40

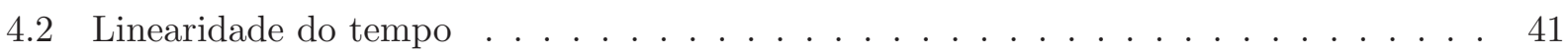

4.3 Tempo da funcão PAR no ACGS em relacão aos bits dos operandos $(m=16)$. . . 42

4.4 Número de amostras em relacão à vantagem do oráculo. . . . . . . . . . . . . . . 44

4.5 Tempo da funcão BKGCD em relacão aos bits dos operandos. . . . . . . . . . . . . 46

4.6 Tempo da funcão PAR no DHCE em relacão aos operandos $(m=40000)$. . . . . . 49

4.7 Tempo da função PAR no DHCE com o oráculo $\mathcal{B}_{p}(m=50$ e $m 2=10)$. . . . . . . 51 


\section{Lista de Tabelas}

2.1 Recomendacões para o tamanho das chaves do NIST 2011 . . . . . . . . . . . 17

4.1 Amostragem em relacão aos bits e à vantagem do oráculo . . . . . . . . . . . . . . 42

4.2 Comparacão entre as complexidades existentes. . . . . . . . . . . . . . 47

4.3 Tempos estimados para execucão do algoritmo ACGS . . . . . . . . . . . . . 48

4.4 Tempos estimados para execucão do algoritmo BS. . . . . . . . . . . . . . . 50

4.5 Tempos estimados para execucão do algoritmo BS usando o oráculo $\mathcal{B}_{n}$. $\ldots . . . \quad 52$

4.6 Tempos estimados para execução do algoritmo JV usando o oráculo $\mathcal{B}_{p} \ldots \ldots$. . . . . 52 


\section{Lista de Algoritmos}

1.1 Gerador pseudoaleatório de Blum, Blum e Shub. . . . . . . . . . . . . . . . . 3

2.1 Gerador pseudoaleatório baseado no RSA. . . . . . . . . . . . . . . . . 20

2.2 Gerador pseudoaleatório de Micali e Schnorr. . . . . . . . . . . . . . . . . . . . . . 20

3.1 Inversor ACGS para o RSA . . . . . . . . . . . . . . . . . . . . 28

3.2 Função de paridade PAR . . . . . . . . . . . . . . . . . . . . . . . . . . . . 29 


\section{Capítulo 1}

\section{Introdução}

Os sistemas de computação atuais muitas vezes requerem que alguma parte dos dados que manipulam sejam protegidos de acessos indiscriminados. A segurança desses dados geralmente recorre a algum tipo de técnica criptográfica.

A criptografia de dados possui algoritmos criptográficos básicos. Alguns desses algoritmos se baseiam em algum problema computacional sem solução eficiente na atualidade, sendo assim considerado um problema difícil - podemos citar o problema do logaritmo discreto (PLD) e o problema da fatoração de inteiros (PFI), queira ver Seção 2.3 (pág. 131). As relações entre esses algoritmos e seus problemas são frequentemente alvos de pesquisas, por exemplo, a verificação de equivalência entre os algoritmos e seus respectivos problemas subjacentes.

Os algoritmos criptográficos por sua vez são utilizados dentro de protocolos criptográficos. Tais protocolos definem regras de como esses algoritmos devem ser utilizados, por exemplo, o cenário, pré-condições, quem se comunica com quem e em que ordem.

Dentro dos protocolos (às vezes, dentro dos próprios algoritmos) ocorrem casos onde são necessários o uso dos chamados números pseudoaleatórios, q.v. Seção 2.7 (pág. 17). Muitos estudos são feitos entorno desses números, podemos separar esses estudos em dois grupos, o primeiro tendo foco apenas estatístico e o segundo tendo foco criptográfico. Assim, a partir dessa divisão, é possível notar que apesar de um modelo conseguir definir estatisticamente um número como sendo aleatório, pode acontecer do modelo não conseguir alcançar que esse número seja considerado também criptograficamente seguro. Nosso trabalho se concentra somente em geradores de números pseudoaleatórios criptograficamente seguros.

Pesquisas interessantes têm aparecido relacionando a segurança dos algoritmos e protocolos criptográficos com os bits que compõem as chaves secretas ou as mensagens encriptadas por esses sistemas ([GMT82, BOCS83, ACGS88, BS01, JV08]), em especial, com o bit menos significativo (LSB - Least Significant Bit).

Esses estudos analisam o algoritmo RSA e o protocolo Diffie-Hellman sobre Curvas Elípticas (DHCE) (q.v. Capítulo 2 de fundamentos) - enquanto no RSA o interesse está no LSB da mensagem original, no DHCE está no LSB da chave secreta combinada. Nos estudos com RSA, o algoritmo Rabin também é abordado por sua similaridade. O algoritmo de encriptação Rabin [Rab79], em 
particular, tem uma prova de equivalência com o PFI.

Com relação aos trabalhos concernentes ao Rabin, partindo da suposição matemática da dificuldade de resolução do PFI, temos os seguintes resultados:

- se alguém resolver esse problema, o Rabin também pode ser resolvido;

- adicionalmente foi provada uma redução do Rabin para a fatoração;

- como consequência, o Rabin e a fatoração são equivalentes;

- adivinhar o LSB da mensagem no Rabin é tão difícil quanto descobrir toda a mensagem;

- em decorrência, predizer o LSB é tão difícil quanto o problema subjacente.

A Figura 1.1 resume esses resultados.

Fatoração de inteiros $\Longleftrightarrow$ Rabin $\Longleftrightarrow$ LSB do Rabin

Figura 1.1: Relações entre as provas.

Em resumo, o que a Figura 1.1 nos diz é que o LSB é seguro, ou seja, ninguém consegue determinar se ele é 0 ou 1 com uma probabilidade maior que 50\% (a não ser que consiga também resolver o PFI de forma eficiente).

Agora suponhamos construir um número pseudoaleatório de $\ell$ bits conforme o Algoritmo 1.1 de Blum, Blum e Shub BBS86]. Deixando de lado os detalhes do algoritmo Rabin para o módulo $N$ e a semente $s$, observe que a operação $x^{2}$ da Linha 8 é a encriptação Rabin. O número final de $\ell$ bits é obtido com a concatenação do LSB de sucessivas encriptações Rabin. O resultado é um número pseudoaleatório que passa por testes estatísticos (comprovando sua distribuição uniforme) e ainda protegido pela segurança do Rabin.

\subsection{Trabalhos relacionados}

Em 1982, Goldwasser, Micali e Tong GMT82 mostraram que se alguém tiver acesso a um oráculo que, dada uma mensagem encriptada pelo RSA, retorna o LSB da mensagem original, então é possível construir um algoritmo de tempo polinomial para recuperar toda a mensagem. Assim, provaram que determinar o LSB é equivalente a inverter o RSA.

Em 1983, Ben-Or, Chor e Shamir [BOCS83 mostraram que também era possível recuperar a mensagem com o uso de oráculo que fosse falho, acertando o LSB em pelo menos $75 \%$ das consultas. Na época, o método encontrado possuía uma limitação que fazia a probabilidade de erro dobrar, impedindo o uso de oráculos com probabilidade de acerto menor. Adicionalmente, os autores provaram que a segurança do primeiro bit é igual a do segundo e que não apenas o LSB é seguro (tão difícil quanto o todo), mas quase todos os outros bits. 


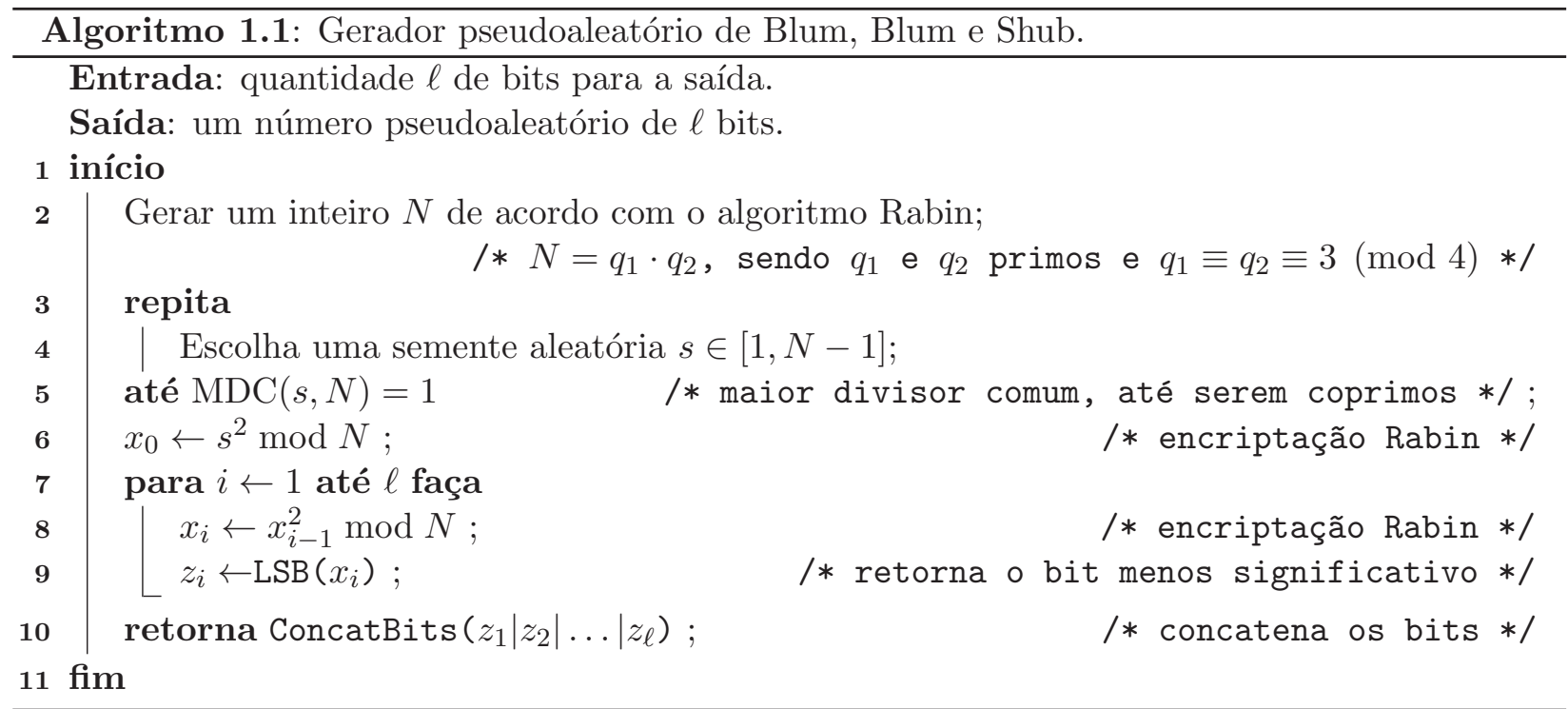

Em 1988, Alexi, Chor, Goldreich e Schnorr ACGS88 conseguiram superar as limitações do trabalho anterior e mostraram ser possível inverter o RSA com um oráculo com probabilidade de acerto de $(50+\varepsilon) \%$, onde $\varepsilon$ é bem pequeno, todavia não negligenciável. Vamos chamar esse trabalho (e o respectivo algoritmo) de ACGS por brevidade. Com esse resultado, o LSB passou a ser considerado imprevisível (a menos que seja resolvido o problema subjacente do RSA). Adicionalmente, para um RSA de módulo $N$, provaram que os $\lg \lg N$ bits menos significativos são seguros.

Em 1996, Boneh e Venkatesan [BV96] mostraram que dentro de um PLD com módulo P, os $\sqrt{\lg P}$ bits mais significativos (MSBs - Most Significant Bits) da chave são seguros. Ou seja, tomando como chave secreta a abscissa de um ponto combinado pelo DHCE, esses $\sqrt{\lg P}$ MSBs da abscissa são seguros — tão difíceis de calcular quanto toda a chave.

Em 1997, Fischlin e Schnorr [FS97] apresentaram uma nova abordagem para o ACGS. Mais tarde, em 2000, eles reapresentaram o trabalho em [FS00], corrigido e de maneira mais completa. Eles mostraram que o ACGS apesar de ter um tempo de execução assintoticamente menor que o tempo para solucionar o PFI, para valores práticos do RSA (1000 bits e 5000 bits, na época), o tempo do ACGS acabava por não ser melhor do que de fatorar inteiros. Por outro lado, mostraram que o novo algoritmo proposto tinha tempo de execução menor que o melhor algoritmo conhecido para solucionar o PFI. Além disso, utilizando conceitos de teoria da informação, mostraram que nesse novo método a quantidade de acessos ao oráculo é bastante próximo ao mínimo necessário. Vamos chamar esse trabalho (e o respectivo algoritmo) de FS por brevidade.

Em 2001, Boneh e Shparlinsk BS01 mostraram que o LSB da abscissa do ponto combinado é imprevisível. Os autores conseguiram alcançar esses resultados fazendo o oráculo trabalhar dentro de certas famílias de curvas elípticas (a família de curvas era definida através de isomorfismo). Vamos chamar esse trabalho (e o respectivo algoritmo) de BS.

Em 2008, Jetchev e Venkatesan [JV08] expandiram o resultado anterior para isogenias entre curvas, chamaremos esse trabalho (e o respectivo algoritmo) de JV. 
Com base nesse resumo dos trabalhos podemos dar continuidade à Figura 1.1 e estabelecer a Figura 1.2. Ela ilustra como o conhecimento do fato do LSB ser imprevisível leva à construção de números pseudoaleatórios: se existisse um oráculo para o LSB do Rabin, então podemos inverter facilmente o Rabin, consequentemente, o PFI não seria difícil; por outro lado, nós já assumimos o PFI provavelmente difícil (já que até hoje não foi encontrada uma solução eficiente) e portanto, é suposto também provável que tal oráculo também não exista; e como o oráculo não existe, não há ninguém que consiga prever o LSB com probabilidade superior a 50\%; por fim, sendo o LSB imprevisível, um número pseudoaleatório construído com esses LSBs também é imprevisível e portanto seguro.

$\begin{aligned} \exists \text { oráculo para o LSB } & \longrightarrow \text { invertemos o Rabin } \\ \text { invertemos o Rabin } & \Longleftrightarrow \text { o PFI não é difícil } \\ \text { mas nós assumimos o PFI difícil } & \Longleftrightarrow \nexists \text { oráculo para o LSB } \\ \nexists \text { oráculo para o LSB } & \Longleftrightarrow \text { LSB é imprevisível } \\ \text { LSB é imprevisível } & \Longleftrightarrow \text { pseudoaleatório é imprevisível }\end{aligned}$

Figura 1.2: Relações entre as provas e o oráculo.

A seguir, citamos alguns trabalhos recentes a título de interesse, não sendo efetivamente utilizados nessa dissertação.

Em 2009, Chevalier, Fouquen, Pointcheval e Zimmer [CFPZ09] apresentaram um método para extrair aleatoriedade de uma fonte de entropia. Onde trabalhos anteriores conseguiam extrair 82 bits de uma curva elíptica de 200 bits, os autores extraem 102 bits com a mesma equivalência estatística.

Em 2009, Hofheinz e Kiltz [HK09] propõem um criptossistema que é seguro contra ataque ativo fazendo uma redução ao PFI. O esquema se utiliza dos trabalhos de ACGS, FS e do Algoritmo 1.1.

Em 2010, Roh e Hahn [RH10, a partir dos resultados de [BV96], provaram a segurança dos $\sqrt{\lg p}$ MSBs, só que para um caso diferente do protocolo Diffie-Hellman.

\subsection{Objetivos e motivação}

Nos trabalhos relacionados, os algoritmos desenvolvidos utilizam oráculos para auxiliá-los. Tais oráculos erram com determinada porcentagem. Assim, os algoritmos que o utilizam são probabilísticos, entretanto mantêm o tempo polinomial, pois possuem uma convergência na probabilidade para a resposta desejada.

O trabalho de FS mostrou como esses algoritmos podem ser pesados (no sentido de tempo de execução), a ponto de ultrapassar o tempo de execução de soluções para problemas difíceis. Aqui surgiram as primeiras dúvidas. Os trabalhos são apresentados apenas como artigos científicos, imaginávamos como eles se comportariam depois de implementados. Apesar de apresentarem con- 
vergência teórica, queremos verificar se ela se traduz na prática com o uso dos geradores de aleatoriedade que dispomos. Ainda, se o tempo real de computação é viável com recursos computacionais modestos.

Uma vez saindo do campo teórico, quando certificado o uso prático de tais métodos, poderíamos fazer uma ligação com ataques de canal secundário (side channel attack). Tais ataques utilizam-se de aspectos físicos e de implementações ruins para obter alguma informação sobre o segredo do criptossistema, como por exemplo, através do tempo de computação, consumo de energia, pico eletromagnético etc. No nosso caso, uma implementação ruim poderia deixar escapar alguma informação sobre o valor do LSB, e tal detalhe, funcionaria como um oráculo.

Como objetivo original, queríamos implementar o trabalho de JV sobre curvas elípticas. Entretanto, ele teve origem do trabalho de BS, que por sua vez era fortemente baseado no trabalho de ACGS. Então, decidimos implementar esses dois últimos também e conseguímos resultados bastante interessantes. Por fim, a implementação de JV foi abandonada devido ao fato de tempo de execução aumentar muito em relação ao seu precedente e não permitir a execução prática.

Implementamos o ACGS para o RSA e em seguida o BS para DHCE. O algoritmo FS foi considerado mais tarde, ele é similar ao ACGS e até mais rápido. Contudo, o FS não foi implementado, uma vez que já tínhamos uma implementação para o RSA e a construção ser bem mais complexa.

Como parte secundária dos objetivos, queríamos identificar os parâmetros que mais influenciavam no tempo de execução, procurando encontrar onde erros eram superestimados e promover melhorias no modo como os oráculos eram utilizados. Ao final, inferimos o tempo de execução para o método de JV baseado nos tempos do trabalho precedente.

\subsection{Contribuições}

As principais contribuições deste trabalho são as seguintes:

- provê uma implementação da segurança do LSB no algoritmo RSA;

- provê uma implementação da segurança do LSB no protocolo DHCE;

- identificação dos parâmetros relevantes para o tempo de execução;

- identificação dos erros superestimados;

- inferimos o tempo de execução para o método de JV;

- conseguimos uma redução no limitante da função de paridade;

- encontramos uma melhoria significativa no número de acessos ao oráculo;

- com as melhorias, o ACGS passou a ser mais rápido que o PFI para valores práticos. 


\subsection{Organização do trabalho}

No Capítulo 2 de fundamentos, apresentamos os conceitos necessários para a compreensão da metodologia desenvolvida nessa dissertação. No Capítulo 3 são descritos os algoritmos dos trabalhos utilizados e as técnicas utilizadas para a implementação desses. Os resultados obtidos são expostos e discutidos no Capítulo 4. Por fim, no Capítulo 5, concluímos a pesquisa e propomos novas direções de trabalhos.

Os teoremas são normalmente apresentados sem provas e quando assim, são acompanhados de uma referência para a demonstração.

O fim das provas de teoremas são sinalizadas com um quadrado branco representando o c.q.d. (como queríamos demonstrar). Adicionalmente, simbolizamos com um quadrado preto o final de definições, exemplos, teoremas etc. que tomam mais de um parágrafo, isso ajuda o leitor a reparar quando estamos retornando ao corpo normal do texto. 


\section{Capítulo 2}

\section{Fundamentos}

Neste capítulo serão introduzidos alguns dos conceitos necessários para a compreensão dos métodos desenvolvidos em nosso trabalho. Apresentamos uma introdução sobre álgebra abstrata, aritmética de curvas elípticas, problemas difíceis, sistemas criptográficos, níveis de segurança, geradores de números aleatórios, oráculos, cálculos para o maior divisor comum (MDC) e alguma matéria sobre probabilidade e estatística.

\section{1 Álgebra abstrata}

Álgebra abstrata é a parte da álgebra que estuda as estruturas algébricas como grupos, anéis e corpos. Com esta seção tendo caráter introdutório, o leitor pode aprofundar a leitura sobre o assunto no livro de Fraleigh [Fra03]. Grande parte do material dessa seção deve referência a este livro. Vamos iniciar nosso estudo matemático com o conceito de grupo, que é utilizado dentro dos sistemas criptográficos desse trabalho.

Definição 2.1.1. Um grupo $\langle G, *\rangle$ é um conjunto $G$ fechado sob uma operação binária $*: G \times G \mapsto$ $G$, tal que os seguintes axiomas sejam satisfeitos:

$$
\begin{array}{r}
\forall a, b, c \in G:(a * b) * c=a *(b * c) \\
\exists e \in G \mid \forall x \in G: e * x=x * e=x \\
\forall a \in G, \exists a^{\prime} \in G: a * a^{\prime}=a^{\prime} * a=e
\end{array}
$$

(associatividade de $*$ )

(elemento identidade $e$ para $*$ )

(inverso $a^{\prime}$ de $a$ )

Muitas vezes a notação $\langle G, *\rangle$ pode ser simplificada para apenas $G$. Quando necessário, pode-se especificar "o grupo $G$ sob a operação *". Por exemplo, podemos nos referir aos grupos $\mathbb{Z}, \mathbb{Q}$ e $\mathbb{R}$ sob adição.

Podemos definir um grupo $\langle G, \oplus\rangle$ e chamá-lo grupo aditivo, com a operação $\oplus$ sendo a operação de adição usual + . Porém, como abuso de notação, denominamos um grupo $\langle G,+\rangle$ aditivo, mesmo quando a operação + não é a operação de adição usual. Por questão meramente notacional, o mesmo 
ocorre para o grupo multiplicativo $\langle G, \otimes\rangle$. A notação para o grupo aditivo e multiplicativo, compele a definir notações usuais para cada uma, vamos discutir os dois casos a seguir.

Notação. A operação em um grupo aditivo $G$ é representada por $a+b$. O elemento neutro $e$ é normalmente denominado 0 . O inverso $a^{\prime}$ de um elemento $a$ é definido $-a$. A repetição da operação de adição é escrita como uma multiplicação por um inteiro $k$ :

$$
k a=\underbrace{a+a+\ldots+a}_{k \text { vezes }}
$$

Notação. A operação em um grupo multiplicativo $G$ é representada por $a \cdot b$ ou simplesmente $a b$. O elemento neutro $e$ é normalmente denominado 1. O inverso $a^{\prime}$ de um elemento $a$ é definido $a^{-1}$ ou $\frac{1}{a}$. A repetição da operação de multiplicação é escrita como uma potenciação por um inteiro $k$ :

$$
a^{k}=\underbrace{a \cdot a \cdot \ldots \cdot a}_{k \text { vezes }}
$$

Nós utilizamos elemento identidade e elemento neutro como sinônimos.

Definição 2.1.2. Um subconjunto $H$ de um grupo $G$ é um subgrupo de $G$ se for fechado sob a operação binária de $G$ e constituir por si só um grupo.

Outra maneira mais detalhada para se definir subgrupo é dada pelo Teorema 2.1.3.

Teorema 2.1.3. [Fra03, Theo.5.14] Um subconjunto $H$ de um grupo $G$ é um subgrupo de $G$ se, e somente se:

- H é fechado sob a operação binária de $G$;

- o elemento identidade e de $G$ está em $H$;

- $\forall a \in H, a^{\prime} \in H$.

Definição 2.1.4. Considere $G$ um grupo e um elemento $a \in G$. Então, o subgrupo $H=\left\{a^{k} \mid k \in \mathbb{Z}\right\}$ de $G$ é chamado subgrupo cíclico de $G$ gerado por $a$ e é denotado por $\langle a\rangle$. Neste caso, $a$ é chamado gerador de $H$.

É possível provar que $\langle a\rangle$ é o menor subgrupo de $G$ que contém $a$ [Fra03, Theo.5.17].

Definição 2.1.5. A ordem $|G|$ de um grupo $G$ é o número de elementos em $G$. Pode ser finita ou infinita.

Definição 2.1.6. Sendo $G$ um grupo finito, a ordem de um elemento $a \in G$ é $|a|=m$, onde $m$ é o menor inteiro positivo tal que $a^{m}=e$, ou seja, igual a identidade $e$.

Dessas definições, verificamos que dado um grupo cíclico finito $G=\left\{a^{k} \mid k \in \mathbb{Z}\right\}=\langle a\rangle$, a ordem de $a$ é igual a ordem $|\langle a\rangle|$ do grupo. 
Definição 2.1.7. Um grupo $G$ é abeliano se sua operação binária é comutativa.

Teorema 2.1.8. [Fra03, Theo.6.1] Todo grupo cíclico é abeliano.

Definição 2.1.9. Um anel $\langle R, \oplus, \otimes\rangle$ é um conjunto $R$, com duas operações binárias $\oplus$ e $\otimes$ - as quais nós chamamos adição e multiplicação — definidas sobre $R$, tal que os seguintes axiomas são satisfeitos:

$\langle R, \oplus\rangle$ é um grupo abeliano

a multiplicação é associativa

$$
\forall a, b, c \in R: a \cdot(b+c)=(a \cdot b)+(a \cdot c)
$$$$
\forall a, b, c \in R:(a+b) \cdot c=(a \cdot c)+(b \cdot c)
$$

(lei distributiva à esquerda)

(lei distributiva à direita)

Definição 2.1.10. Um anel onde a multiplicação é comutativa é chamado anel comutativo. Um anel com elemento neutro multiplicativo é chamado anel com unidade. Seja $R$ uma anel com unidade $1 \neq 0$ (onde 0 é elemento neutro aditivo), se todo elemento diferente de 0 em $R$ possui inverso multiplicativo, então $R$ é um anel de divisão.

Definição 2.1.11. Um corpo é um anel de divisão comutativo com unidade.

Em vez de utilizar as Definições 2.1.10 2.1.11 para corpo, podemos resumi-las alternativamente com a Definição 2.1.12.

Definição 2.1.12. Um corpo é um anel $\langle\mathbb{F}, \oplus, \otimes\rangle$ onde $\langle\mathbb{F} \backslash\{0\}, \otimes\rangle$ é um grupo abeliano.

Notação. Um corpo $\mathbb{F}$ de ordem $q=p^{m}$ é denotado $\mathbb{F}_{q}$, onde $m$ é um inteiro positivo e $p$ primo. Quando $m=1$ simplesmente notamos $\mathbb{F}_{p}$.

Dessa notação, observamos que $q$ é a ordem do corpo e $p$ a sua característica, Definição 2.1.13,

Definição 2.1.13. Se para um anel $R$ existe um inteiro positivo $k$, tal que, $\forall a \in R: k a=0$, então o menor inteiro positivo $k$ é a característica do anel $R$, denotada char $(R)=k$. Se tal inteiro positivo não existe, então $\operatorname{char}(R)=0$.

Naturalmente, a Definição 2.1.13 de característica aplica-se também a corpo (sendo esse anel).

Observe que da mesma forma para com grupos, as notações $\oplus$ e $\otimes$ para anéis e corpos aqui, não necessariamente correspondem as operações usuais de adição + e multiplicação $\cdot$ Na verdade, veremos mais adiante que temos a multiplicação modular para o RSA e a adição de pontos para curvas elípticas.

Temos o interesse em classificar funções entre elementos de grupos (anel/corpos) diferentes. As próximas duas definições nos dão os conceitos.

Definição 2.1.14. Uma função $\phi$ de um grupo $G$ em outro grupo $G^{\prime}$ é um homomorfismo se a propriedade homomórfica

$$
\phi(a b)=\phi(a) \phi(b)
$$

se mantém $\forall a, b \in G$. 
Definição 2.1.15. Uma função $\phi$ de um grupo $G$ em outro grupo $G^{\prime}$ é um isomorfismo se $\phi$ é bijetora e é um homomorfismo.

\subsection{Curvas elípticas}

Muitas vezes, um leitor não familiarizado com o assunto associa a ideia de curvas elípticas com as equações da elipse. Não é esse o caso aqui. Curva elíptica usada em criptografia é tratada como um grupo $\langle G, \oplus\rangle$ com a operação $\oplus$ de adição de pontos a definir. O material dessa seção deve referência ao livro de Silverman [Sil86] sobre aritmética de curvas elípticas.

Curvas elípticas aplicadas à criptografia foram sugeridas independentemente por Victor S. Miller [Mil86] em 1985 e por Neal Koblitz [Kob87] em 1987. Também, em 1985, H. W. Lenstra Jr. Len87] mostrou um método utilizando curvas elípticas para se fatorar inteiros.

Definição 2.2.1. Uma curva elíptica $E$ sobre um corpo $\mathbb{F}$, denotada $E / \mathbb{F}$, é definida pela equação:

$$
E: y^{2}+a_{1} x y+a_{3} y=x^{3}+a_{2} x^{2}+a_{4} x+a_{6}
$$

onde $a_{1}, a_{2}, a_{3}, a_{4}, a_{5}, a_{6} \in \mathbb{F}$, mais o ponto no infinito (q.v. Definição 2.2.3).

Em uma curva elíptica $E / \mathbb{F}$ com $\operatorname{char}(\mathbb{F})=p$ prima, $p \neq 2, p \neq 3$ e sendo $p$ grande é chamada curva prima. Utilizaremos apenas curvas primas nesta dissertação.

Considerando curvas primas, a Equação (2.1) pode sofrer uma transformação e ser apresentada na forma da equação simplificada de Weierstrass:

$$
E: y^{2}=x^{3}+a x+b
$$

onde $a, b \in \mathbb{F}$.

Simplificamos a notação da curva elíptica $E / \mathbb{F}$ para somente $E$. Em uma curva $E$, os valores $x$ e $y$ que satisfazem a Equação (2.2) definem coordenadas $(x, y)$ chamadas pontos na curva.

Definição 2.2.2. Uma curva elíptica $E$ dada pela equação simplificada de Weierstrass possui um discriminante $\Delta=4 a^{3}+27 b^{2}$. Se $\Delta \neq 0$ então chamamos a curva $E$ de não singular.

As curvas das Figuras 2.1 e 2.2 são exemplos de curvas elípticas não singulares, foram extraídas do livro de Terada [Ter08, pág. 160]. Tome nota que ao incluir gráficos com exemplos de curvas temos objetivo meramente ilustrativo, uma vez que em criptografia o nosso interesse é algébrico e não geométrico. Adicionalmente, as figuras apresentam gráficos contínuos e em criptografia trabalhamos com o caso discreto, ou seja, as coordenadas para curvas elípticas são coordenadas inteiras.

Neste trabalho estamos interessados em curvas elípticas não singulares. Especificamente aqui, nesta dissertação, em curvas de característica prima grande (pelo menos 160 bits). Em uma curva $E$ desse tipo, os pontos de $E$, mais uma operação de adição de pontos e um ponto artificial são utilizados para construir um grupo. 


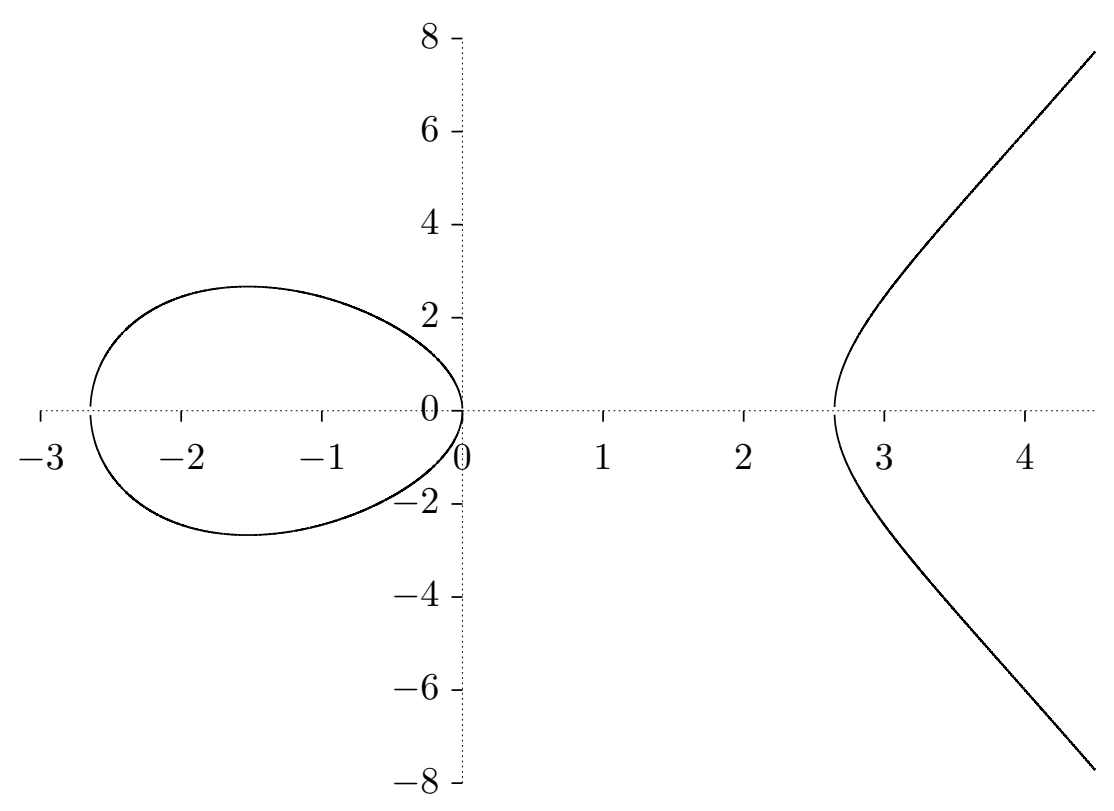

Figura 2.1: Curva elíptica $y^{2}=x^{3}-7 x$

Definição 2.2.3 (Adição de pontos). Seja $Q=\left(x_{q}, y_{q}\right), R=\left(x_{r}, y_{r}\right)$ e $S=\left(x_{s}, y_{s}\right)$ pontos em uma curva prima não singular. Denotamos o inverso de um ponto $Q$ como $-Q=-\left(x_{q}, y_{q}\right)=\left(x_{q},-y_{q}\right)$. Seja o ponto artificial $\infty$, chamado ponto no infinito. Vamos definir a operação de adição de pontos:

- $Q+\infty=\infty+Q=Q$;

- se $R$ é o inverso de $Q$, então $Q+R=Q+(-Q)=\infty$;

- se $R \neq-Q$, então para calcular $Q+R=S$

$$
\text { escolhemos } t= \begin{cases}\frac{y_{r}-y_{q}}{x_{r}-x_{q}} & \text { se } Q \neq R \\ \frac{3 x_{q}^{2}+a}{2 y_{q}} & \text { se } Q=R\end{cases}
$$

e fazemos:

$$
\begin{aligned}
& x_{s}=t^{2}-x_{q}-x_{r} \\
& y_{s}=t\left(x_{q}-x_{s}\right)-y_{q} .
\end{aligned}
$$




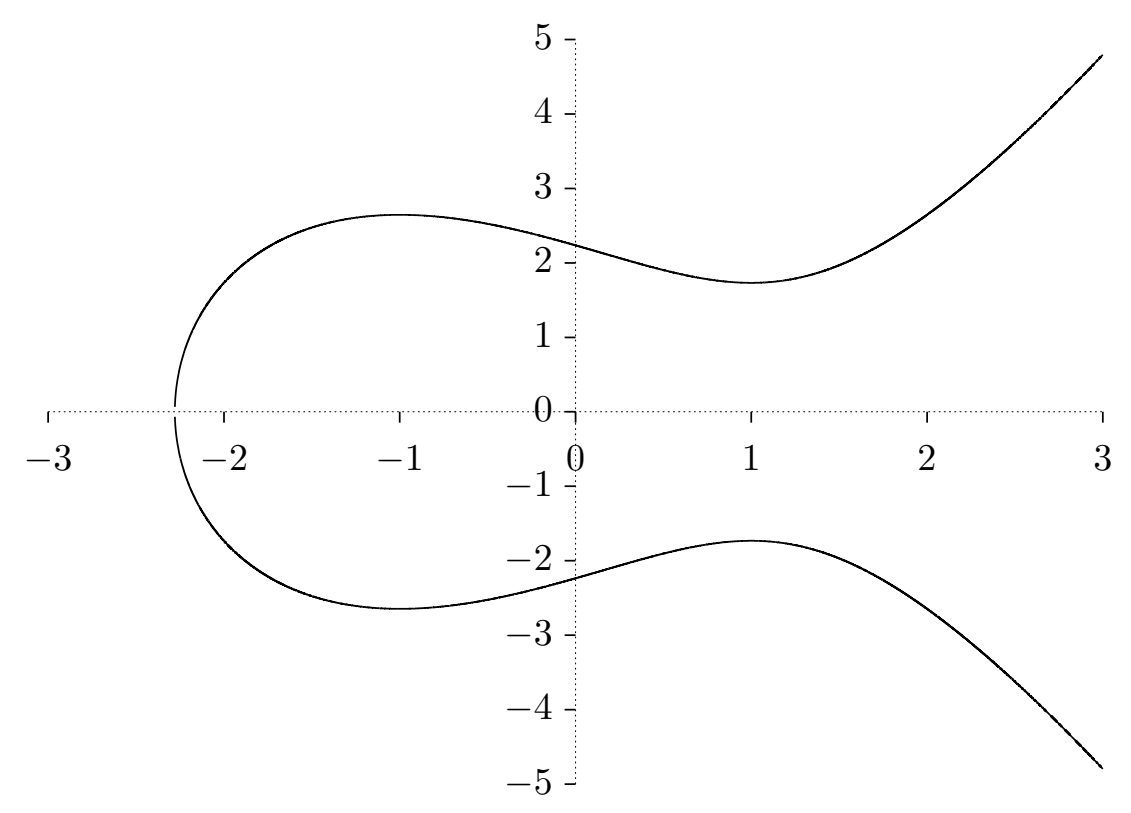

Figura 2.2: Curva elíptica $y^{2}=x^{3}-3 x+5$

Agora podemos definir curva elíptica como grupo.

Definição 2.2.4. Uma curva elíptica $E$ sobre um corpo $\mathbb{F}_{p}$, onde $p \gg 3$ é primo e $\Delta \neq 0$, forma um grupo abeliano aditivo $\langle G, \oplus\rangle$, onde $\oplus$ é a operação de adição de pontos e $G=\left\{(x, y) \in \mathbb{F}_{p} \times \mathbb{F}_{p}\right.$ : $\left.y^{2}=x^{3}+a x+b\right\} \cup\{\infty\}$. O elemento neutro é o ponto no infinito $\infty$. Esse grupo também pode ser denotado $E\left(\mathbb{F}_{p}\right)$.

Nossa Definição 2.2.4 para pontos de uma curva prima como grupo é sustentada por um teorema do livro de Washington [Was08, Theo.2.1].

Agora considere uma curva elíptica $E / \mathbb{F}_{p}$ na forma simplificada de Weierstrass:

$$
E_{1}: y^{2}=x^{3}+a x+b
$$

então existe um isomorfismo $\phi$ de $E_{1}$ em $E_{2}$ [Sil86, III.§10], tal que:

$$
\begin{gathered}
\phi: E_{1} \mapsto E_{2} \\
E_{2}: y^{2}=x^{3}+\left(\lambda^{4} a\right) x+\left(\lambda^{6} b\right)
\end{gathered}
$$

$\operatorname{com} \lambda \in \mathbb{F}_{p}^{*}$.

Os pontos em $E_{2}$ podem ser facilmente calculados, seja $Q=(x, y) \in E$, então $\phi(Q)=\left(\lambda^{2} x, \lambda^{3} y\right)$.

No trabalho de JV vamos precisar da Definição 2.2.5 a seguir. 
Definição 2.2.5. [Sil86, III.§4] Seja $E_{1}$ e $E_{2}$ curvas elípticas. Uma isogenia $\phi$ entre $E_{1}$ e $E_{2}$ é uma função $\phi: E_{1} \mapsto E_{2}$ satisfazendo $\phi(\infty)=\infty$. Dizemos que $E_{1}$ e $E_{2}$ são isógenas se há uma isogenia $\phi$ entre elas com $\phi\left(E_{1}\right) \neq\{\infty\}$.

Sem muito aprofundamento, vamos declarar as propriedades de isogenias de uso no trabalho de JV. Para uma isogenia $\phi$ de grau $d$ existe uma isogenia $\hat{\phi}: E_{2} \mapsto E_{1}$ chamada isogenia dual Sil86, Theo.6.1], onde a composição $\phi \circ \hat{\phi}=[d]$. Aqui, $[d]$ denota a função em que dado um ponto $Q$, calculamos $[d](Q)=d Q$.

\subsection{Problemas difíceis e notação assintótica}

Um problema computacional considerado difícil é um problema cuja melhor solução conhecida não é eficiente. Essa terminologia se refere à complexidade do algoritmo utilizado para solucionar o problema. Para entender melhor o conceito, precisamos primeiro definir notação assintótica.

Vamos definir a notação assintótica $O()$. Seja $f(n)$ a função que define o tempo de execução de um algoritmo no pior caso, isso em função do tamanho da entrada $n$. Escrevemos $f(n)=O(g(n))$ se existe uma constante $c>0$ e um inteiro $n_{0}$ tais que $0 \leq f(n) \leq c g(n)$ para todo $n>n_{0}$. Ou seja, a partir de um $n$ suficientemente grande, a função $f(n)$ não cresce além de $g(n)$ a menos de um fator constante.

Exemplo 2.3.1 (Notação $\mathrm{O}(\mathrm{n})$ ). Seja $f(n)=8 n^{2}+256 n+32768$, então $f(n)=O\left(n^{2}\right)$. Assim, para um $n$ de valor muito grande, o crescimento de $f(n)$ é insignificante comparado a $n^{2}$.

Voltando agora a complexidade de algoritmos, um algoritmo é considerado de tempo polinomial se sua função $f(n)$ de tempo de execução no pior caso é igual a $f(n)=O\left(n^{k}\right)$ para uma constante $k$. Por outro lado, ele é considerado de tempo exponencial se tal constante não existe.

Existe consenso nas definições de que um algoritmo de tempo polinomial é considerado computacionalmente eficiente (também dito viável ou fácil) e um de tempo exponencial é considerado computacionalmente ineficiente (também dito inviável ou difícil).

Em Ciência da Computação, a criptografia empresta problemas difíceis da matemática para construir sistemas criptográficos baseados na dificuldade computacional dos algoritmos de solução relacionados. Vamos apresentar dois problemas de interesse, PLD e PFI.

Definição 2.3.2 (Problema do logaritmo discreto). Dados inteiros $\{y, x, N\}$ de modo que $y \equiv$ $x^{s} \bmod N$ para algum inteiro $s$ desconhecido. Não é possível calcular $s$ de modo eficiente. Chamamos $s$ de logaritmo discreto porque é possível representar $s \equiv \log _{x} y(\bmod N)$.

Usando a notação aditiva para o $\operatorname{PLD}$, dado $Q \in\langle G\rangle \operatorname{com}|G|=q$, temos que computar $s$ tal que $Q \equiv s G \bmod q$.

Definição 2.3.3 (Problema da fatoração de inteiros). Dado o inteiro $N$ de modo que $N=q_{1} \cdot q_{2}$ para primos grandes $q_{1}$ e $q_{2}$ não conhecidos. Não é possível calcular os fatores $q_{1}$ ou $q_{2}$ de modo eficiente. 


\section{$2.4 \quad$ RSA}

O algoritmo criptográfico RSA foi proposto em 1978 por Rivest, Shamir e Adleman RSA78. Ele é baseado na dificuldade computacional de fatorar um número inteiro em primos.

Vamos supor que dois usuários querem se comunicar, nesse caso, um usuário B precisa enviar uma mensagem $x$ para um usuário A. Por facilidade, devida às iniciais, geralmente os usuários A e B são chamados de Alice e Beto. Assim, resumimos o algoritmo conforme:

1. Alice escolhe dois primos grandes $q_{1}$ e $q_{2}$ e calcula seu produto $N=q_{1} \cdot q_{2}$;

2. Alice escolhe um valor $e$ de modo que seja relativamente primo a $\Phi(N)$;

3. Alice calcula o inverso $d$ de $e$ módulo $\Phi(N)$, ou seja, $d \cdot e \equiv 1 \bmod \Phi(N)$;

4. Alice divulga sua chave pública $(e, N)$ e mantém em segredo sua chave privada $(d, N)$;

5. Beto encripta a mensagem $x$ calculando $y \equiv x^{e} \bmod N$ e envia $y$ para Alice;

6. Alice ao receber $y$, decripta a mensagem calculando $x \equiv y^{d} \bmod N$.

O símbolo $\Phi(N)$ representa aqui a função Phi de Euler, neste caso especificamente, $\Phi(N)=$ $\Phi\left(q_{1}\right) \Phi\left(q_{2}\right)=\left(q_{1}-1\right)\left(q_{2}-1\right)$. O fato de $s$ precisar ser coprimo com $\Phi(N)$ é uma exigência algébrica para encriptação única. O fato de $d$ ter que ser o inverso de $s$ é o que permite a decriptação.

Note que ao se veicular o valor $y$ em um meio público, não é possível recuperar a mensagem $x$ de maneira eficiente, a não ser que se conheça a chave privada de Alice. Ainda, a descrição do RSA utilizada aqui é uma versão plana, não consideramos nesse trabalho a adição de paddings.

O algoritmo RSA é protegido pelo PFI, pois se fosse possível descobrir os fatores $q_{1}$ e $q_{2}$, seria fácil calcular $\Phi(N)$ e consequentemente achar o inverso de $e$ (usando por exemplo, o algoritmo de Euclides estendido). Em relação ao PFI, pede-se que $q_{1}$ e $q_{2}$ além de serem grandes, sejam ainda de tamanhos (em bits) próximos para dificultar a fatoração.

Um ponto necessário a se salientar é sobre a propriedade multiplicativa do RSA. Suponhamos que temos a mensagem encriptada $y$, ou seja, $y \equiv x^{e} \bmod N$. Em nossos métodos, desejamos obter o valor $z \equiv(c x)^{e} \bmod N$ para alguma constante $c$. Não podemos simplesmente multiplicar $c$ por $x$ e depois encriptar, isso é porque não sabemos o valor de $x$. Contudo, utilizando a propriedade multiplicativa do RSA podemos computar $z$ da seguinte forma:

- encriptamos $c$ em $t \equiv c^{e} \bmod N$;

- tomamos o produto $z \equiv t y \bmod N$;

- e já temos o valor desejado, observe: $z \equiv t y \equiv\left(c^{e}\right)\left(x^{e}\right) \equiv(c x)^{e}(\bmod N)$;

- foi possível obter $z$ sem conhecer os valor da mensagem original $x$. 
Um outro fato importante é sobre a divisão dentro da aritmética modular. Tal operação não é explicitamente definida e em nosso trabalho estamos interessados em efetuar divisões por 2 . O que na realidade fazemos é multiplicar o número desejado pelo inverso multiplicativo de 2 . Veja os três exemplos a seguir.

Exemplo 2.4.1. Calculamos $I \equiv 2^{-1} \bmod N$, ou seja, $2 I \equiv 1 \bmod N$. Para se dividir por 2 o número 82 fazemos $82 \cdot I \equiv 41 \bmod N$.

Exemplo 2.4.2. Aqui, calculamos o inverso de 2 para um módulo $N=15$, que no caso é $I \equiv$ $8 \bmod 15$. É curioso notar a possibilidade de "dividir por 2" um número ímpar, assim calculamos $7 \cdot I \equiv 11 \bmod 15$. Geralmente o resultado não é intuitivo para o leitor, então vejamos de outro modo: como $N$ sempre é ímpar (por ser produto de primos ímpares), o próximo elemento congruente módulo $N$ sempre será par, nesse caso $7+N=22$, a partir daí é fácil para o leitor enxergar que $7 \cdot I \equiv 22 \cdot I \equiv 11(\bmod 15)$.

Exemplo 2.4.3. Vamos agora calcular o inverso de 2 módulo $N$ considerando a propriedade multiplicativa do RSA. Dada uma mensagem encriptada $y$ (correspondente à mensagem original $x$ ), temos o interesse de obter um valor $z$ que corresponda ao criptograma da mensagem $x$ "dividida por 2", ou seja, computar $z=\operatorname{RSA}\left(\frac{x}{2}\right)$. Mesmo não conhecendo o valor de $x$ o cálculo é possível da seguinte forma:

- encriptamos 2 em $t \equiv 2^{e} \bmod N$;

- calculamos o inverso de $t$ módulo $N$, tal que $I \equiv 2^{-e} \bmod N$;

- tomamos o produto $z \equiv I y \bmod N$;

- e já temos o valor desejado, observe: $z \equiv I y \equiv\left(2^{-e}\right)\left(x^{e}\right) \equiv\left(2^{-1} x\right)^{e}(\bmod N)$.

A propriedade multiplicava e os modos de se calcular a divisão por 2 são utilizados nos algoritmos ACGS e derivados. Note que cálculos similares serão feitos em curvas elípticas.

Notação. Nesse trabalho adotamos a convenção de notar o módulo $N$ com letra maiúscula e seu tamanho em bits $n=\lfloor\lg N\rfloor+1$ com letra minúscula.

\subsection{Diffie-Hellman sobre curvas elípticas}

Em 1976, Diffie e Hellman DH76 propuseram um protocolo de troca de chaves que revolucionou a área da criptografia. A partir disso, houve o nascimento da criptografia da chave pública, também chamada de criptografia assimétrica.

O protocolo também resolvia em parte o problema de estabelecimento de chaves em comum na criptografia simétrica, também chamada criptografia de chave secreta. Por exemplo, no DES ou AES quando os usuários estão distantes geograficamente eles precisavam combinar secretamente 
uma chave em comum para utilizar esses algoritmos (mais informações sobre esses algoritmos no livro de Terada [Ter08]).

Enquanto em criptografia simétrica as duas partes compartilham uma única chave em comum, chamada chave secreta, na criptografia assimétrica cada parte possui duas chaves, chamadas chave pública e chave privada. Já vimos um exemplo na Seção 2.4 anterior (pág. 14), o RSA é um algoritmo criptográfico de chave pública.

Além de curvas elípticas serem utilizadas dentro de algoritmos criptográficos, elas também são utilizadas para criar acordo de chaves. Nessa seção, vamos descrever o protocolo de acordo de chaves Diffie-Hellman sobre Curvas Elípticas (DHCE).

Digamos que Alice e Beto estão distantes geograficamente e querem se comunicar. Decidem utilizar o AES por ser rápido e seguro. Previamente, ambos conhecem publicamente uma curva prima $E$ e um ponto gerador $G$ de ordem $q$. Para estabelecer uma chave em comum eles executam os seguintes passos:

1. Alice escolhe um número aleatório $a \in[1, q-1]$;

2. Beto escolhe um número aleatório $b \in[1, q-1]$;

3. Alice calcula $Q=a G$ e envia $Q$ para Beto;

4. Beto calcula $R=b G$ e envia $R$ para Alice;

5. Alice obtém a chave comum calculando $K_{a b}=a R$;

6. Beto obtém a chave comum calculando $K_{a b}=b Q$.

Ao final do protocolo, ambos podem usar $K_{a b}$ para derivar uma chave secreta para o AES e se comunicar. O protocolo é protegido pelo PLD. Por outro lado, não oferece autenticação para as partes, permitindo um ataque conhecido como homem do meio (man-in-the-middle). Não vamos nos preocupar nessa dissertação com tal ataque. Assim, usamos a versão simplificada conforme foi descrita.

Um simples exercício de cálculos nos leva a enxergar que as chaves $K_{a b}$ calculadas por cada uma das partes são iguais de fato. Partindo da chave de Alice:

$$
\begin{aligned}
K_{a b} & =a \cdot R \\
& =a \cdot b G \\
& =b \cdot a G \\
& =b \cdot Q
\end{aligned}
$$

Notação. Nesse trabalho adotamos a convenção de notar a característica $p$ do corpo da curva com letra minúscula e seu tamanho em bits igual a $\lg p$ sendo o mesmo que $\lfloor\lg p\rfloor+1$. 


\subsection{Tamanho das chaves}

Até agora, temos falado de algoritmos e protocolos como o RSA, DHCE e DES. Cada um deles traz consigo uma definição no tamanho das chaves, o que determina o parâmetro de segurança.

O NIST (National Institute of Standards and Technology) divulga recomendações para o tamanho das chaves 1 . O parâmetro de segurança $k$ é baseado no tamanho de chave para um algoritmo de criptografia simétrica, correspondendo a uma busca exaustiva nas $2^{k}$ possíveis chaves. A Tabela 2.1 resume as recomendações do NIST com os tamanhos recomendados (em bits) e as respectivas validades [NIS11].

\begin{tabular}{clcc} 
Simétrico & Validade & Assimétrico & Curva Elíptica \\
\hline 80 & até 2010 & 1024 & 160 \\
112 & até 2030 & 2048 & 224 \\
128 & além de 2030 & 3072 & 256 \\
192 & - & 7680 & 384 \\
256 & - & 15360 & 512 \\
\hline
\end{tabular}

Tabela 2.1: Recomendações para o tamanho das chaves do NIST, 2011.

O trabalho de FS definiu como valores práticos 1000 bits para o RSA na época. Assim, executamos testes para o ACGS em um RSA de 1024 bits. Seguindo o parâmetro de segurança correspondente $k=80$, executamos testes para o BS em uma curva elíptica de 160 bits para termos uma comparação dos tempos dos métodos em um mesmo nível de segurança.

Como atualmente (a conclusão desta dissertação está prevista para o ano de 2011) o parâmetro de segurança válido é de 112 bits, executamos testes também para um RSA de 2048 bits e para curva elíptica de 224 bits.

Adicionalmente por completude, seguindo FS, executamos testes para um RSA de 5000 bits (não foi executado o correspondente para o DHCE).

Devemos acrescentar que existem outras fontes com recomendações para tamanho de chaves, bem como ferramentas que efetuam comparações entre elas. Apontamos a ferramenta da BlueKrypt, http://www.keylength.com/

\subsection{Números pseudoaleatórios}

Números pseudoaleatórios são números construídos de maneira a parecer que possuem uma distribuição uniforme dentro de um determinado intervalo. Nessa seção, apresentamos os conceitos entorno de tais números mostrando a conexão dessa matéria com o estudo de nossa dissertação. O conteúdo aqui descrito deve referência ao Capítulo 5 do livro de Menezes, Vanstone e Oorschot [MVO96].

\footnotetext{
${ }^{1}$ http://csrc.nist.gov/groups/ST/toolkit/key_management.html
} 
Podemos gerar um número aleatório utilizando um gerador de números aleatórios (RNG). Tal gerador pode-se utilizar de um gerador de bits aleatórios para compor sistematicamente o inteiro aleatório.

Definição 2.7.1. Um gerador de bits aleatório (RBG) é um dispositivo ou algoritmo que produz uma sequência de dígitos binários estatisticamente independentes e uniformes.

Fontes de bits verdadeiramente aleatórios têm como origem meios físicos na prática. Esses, na maioria são lentos e ineficientes. Ainda, pode ser impraticável armazenar com segurança tais fontes de dados e/ou transmitir uma grande quantidade de bits. Alguns exemplos de fontes físicas:

- tempo decorrido entre a emissão de partículas durante um declínio radioativo,

- ruído térmico de um diodo semicondutor ou um resistor,

- a instabilidade de frequência de um oscilador livre,

- a quantidade de carga em um capacitor dentro de um intervalo fixo,

- a turbulência do ar dentro de um disco rígido selado,

- a entrada de som de um microfone,

- a entrada de vídeo de uma câmera etc.

Uma maneira de amenizar o problema seria utilizar um gerador de bits pseudoaleatório (PRBG). Trata-se de um algoritmo que, dada uma sequência binária de entrada chamada semente e de tamanho $k$ bits, gera uma sequência binária de saída com tamanho $l$ bits, onde $l \gg k$. Este gerador é determinístico (para uma mesma semente, gera sempre a mesma sequência de bits) e de todas possíveis sequências binárias, apenas uma fração $\frac{2^{k}}{2^{l}}$ delas poderá ser gerada.

A intenção é conseguir expandir uma pequena sequência de bits verdadeiramente aleatória para uma sequência maior de maneira mais rápida. Embora a saída não seja de fato uniforme, com um bom gerador, nenhum adversário poderá distinguir a saída — de maneira eficiente — de uma sequência verdadeiramente aleatória. A restrição de segurança fica por conta do tamanho $k$ da semente, ela deve ser grande o suficiente para que seja inviável computar todas as possíveis $2^{k}$ sequências.

Utilizamos um PRBG para criar um gerador de números pseudoaleatórios (PRNG). Várias linguagens de programação possuem um PRNG incorporado. As aplicações de PRGNs é variada:

- geração de chaves,

- NONCEs (number used once),

- simulações estatísticas,

- loterias (slot machines), 
- aplicações de pesquisa (Monte Carlo method) etc.

Na criptografia em particular, os NONCE são utilizados, por exemplo, para encriptar um bloco de mensagem. Para cada bloco, um NONCE diferente. Como o próprio nome diz, cada NONCE tem que ser exclusivo. Se um adversário puder prever com alguma vantagem não negligenciável o próximo NONCE, a segurança do algoritmo é comprometida. Daí a necessidade de se utilizar um gerador de números pseudoaleatórios criptograficamente seguro (CSPRNG). O mesmo equivale para o uso de um PRNG na geração de chaves.

Como mencionado na Introdução (Seção1), um gerador pode produzir números estatisticamente uniformes, porém não tendo a propriedade de ser seguro criptograficamente. Nesta dissertação estaremos interessados somente em CSPRNG. O conceito de PRBG criptograficamente seguro foi introduzido por Blum e Micali em 1984 [BM84].

Um gerador que se diz produzir números aleatórios deve ser capaz de passar por vários testes estatísticos padronizados (q.v. Seção 5.4 de [MVO96]). Existe um teste chamado teste do próximo bit que tem caráter universal, ou seja, um PRBG passa em um teste do próximo bit se, e somente se, ele passa em todos os testes estatísticos de tempo polinomial.

Definição 2.7.2 (next-bit test). Um PRBG passa no teste do próximo bit se nenhum algoritmo de tempo polinomial, com entrada de $l$ bits de uma sequência gerada, é capaz de prever o $(l+1)$ ésimo bit da sequência com uma probabilidade de acerto maior que $\frac{1}{2}$.

Naturalmente, um CSPRNG passa nesse teste. Adicionalmente, o CSPRNG também se baseia em uma dificuldade matemática plausível. O CSPRNG de Blum, Blum e Shub descrito no Algoritmo 1.1 (pág. 3) da Seção 1 se baseia no PFI devido ao algoritmo criptográfico Rabin. Deixamos para apresentar com mais detalhes nessa seção dois CSPRNGs baseados no RSA.

O Algoritmo 2.1 é construído sob a suposição de intratabilidade do problema de inversão do RSA (sem a chave de decriptação). Tome-se nota que muito embora saibamos da ligação do RSA com o PFI, ainda não dispomos de uma prova definitiva da equivalência entre os problemas. Esse gerador é descrito em [MV096, Alg.5.35], mas na verdade é baseado no ACGS.

Ao analisar o CSPRNG do Algoritmo 2.1 considere a geração dos parâmetros para o RSA conforme descrito na Seção 2.4 (pág. 14). Observe que na Linha 6 temos uma encriptação RSA. O problema aqui é que para cada bit gerado temos uma encriptação, o que envolve uma exponenciação modular, operação que tem tempo de execução demorado. O tempo pode ser reduzido escolhendo um expoente $e$ o menor possível. Desse ponto de vista, o CSPRNG utilizando Rabin pode ser bem mais rápido por possuir expoente pequeno igual a 2 .

Como o algoritmo agrega o LSB de cada encriptação RSA, o gerador é criptograficamente seguro. Isso é devido ao trabalho de ACGS, já discutido da Seção 1.1 (pág. 2). O Teorema 1 de [ACGS88] estabelece que o LSB do RSA é imprevisível. Ademais, o Teorema 2 do mesmo artigo estabelece que os $O(\lg \lg N)$ bits menos significativos são simultaneamente seguros. Isso permite melhorar ainda mais a eficiência do Algoritmo 2.1. Em vez de na Linha 7 extrairmos apenas 1 bit, podemos extrair aproximadamente $c \lg \lg N$ bits, embora a contante $c$ não seja conhecida exatamente.

O segundo CSPRNG baseado no RSA é devido a Micali e Schnorr em [MS90] e em [MS91]. O gerador é apresentado no Algoritmo 2.2 . 

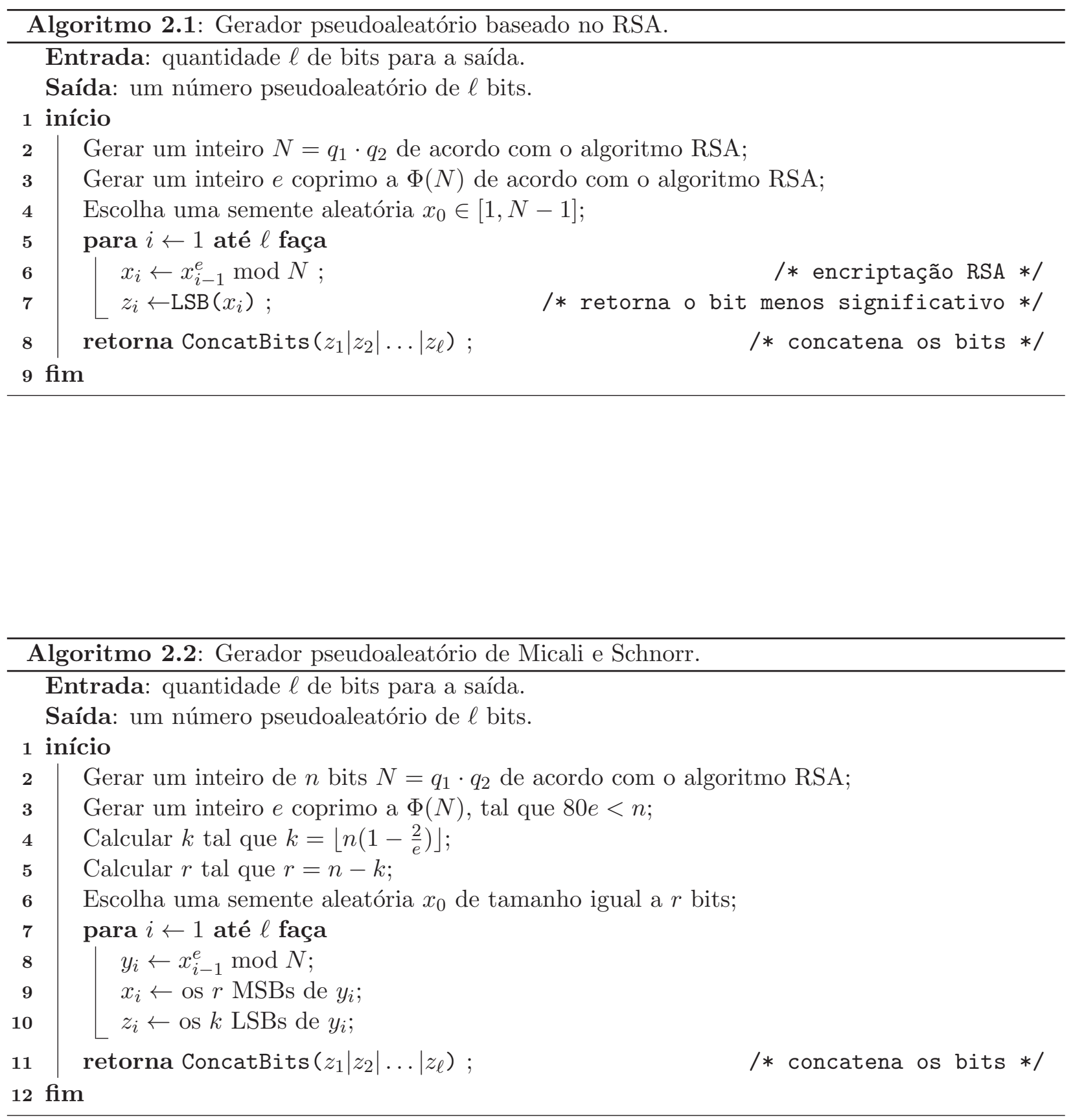
Com a modificação de Micali e Schnorr, o Algoritmo 2.2 é bem mais eficiente que o Algoritmo 2.1 . A cada exponenciação por $e$ são extraídos $\left\lfloor n\left(1-\frac{2}{e}\right)\right\rfloor$ bits. Por outro lado, a suposição matemática adotada é mais forte que a da intratabilidade do RSA. Aqui, a suposição é que a distribuição de probabilidade de $x^{e} \bmod N$ para uma sequência de números $x$ de $r$ bits se aproxima da distribuição uniforme.

O trabalho de FS, em particular, se preocupou em mostrar que a geração de números aleatórios, de acordo com o modelo introduzido por Blum e Micali, possui demonstração de segurança e ainda assume complexidade menor que o problema matemático subjacente, no caso, o PFI.

\subsection{Oráculos}

O que chamamos de oráculo neste trabalho trata-se de um algoritmo que, ao receber como entrada parâmetros públicos de um criptossistema, retorna o LSB da parte secreta desse sistema.

Definição 2.8.1. Dizemos que um oráculo tem vantagem $\varepsilon$ se ele acerta o LSB com uma probabilidade igual ou superior a $\frac{1}{2}+\varepsilon$.

Notação. Por exemplo, para o DHCE em uma curva $E$, gerador $G$ de ordem $q$ e $a, b$ distribuídos uniformemente em $[1, q-1]$, o algoritmo $\mathcal{A}$ é um oráculo com vantagem $\varepsilon$ em predizer o LSB da coordenada $x$ da função Diffie-Hellman e denotamos:

$$
\left.\operatorname{Adv}_{E, G}^{X}(\mathcal{A})=\mid \underset{a, b}{\operatorname{Pr}}[\mathcal{A}(E, G, a G, b G)=\operatorname{LSB}(x)]-\frac{1}{2}\right] \mid>\varepsilon
$$

Observe que a partir dessa notação e da Definição 2.8.1, uma vantagem $\varepsilon$ é qualquer melhoria em computar o LSB além da escolha indiscriminada entre 0 e 1 - que já tem probabilidade igual a 50\%. Porém, essa melhoria deve ser não negligenciável, ou seja, ter tamanho suficiente para ser viável a construção de um algoritmo de tempo probabilístico polinomial que possa recuperar o valor secreto desejado.

Por vezes neste trabalho, falamos de uma função para descobrir a paridade de um valor, isso equivale a descobrir o LSB, já que a paridade é definida por um número possuir um bit 0 ou 1 ao final de sua composição. Embora essa noção seja bastante intuitiva em geral, vamos apresentar uma outra não tão fácil de se enxergar. É devida a análise de Goldwasser, Micali e Tong em [GMT82.

Teorema 2.8.2. GMT82, Example 2] Seja $\mathcal{O}_{1}$ um oráculo para o LSB da mensagem $x$ no RSA de módulo $N$. Considere o oráculo a seguir:

$$
\mathcal{O}_{2}\left(x^{e} \bmod N\right)= \begin{cases}0 & \text { se } x<N / 2 \\ 1 & \text { se } x>N / 2\end{cases}
$$

o oráculo $\mathrm{O}_{2}$ diz, a partir de uma mensagem encriptada, se a mensagem original estava na primeira ou na segunda metade do conjunto do $R S A$. Os oráculos $\mathcal{O}_{1}$ e $\mathcal{O}_{2}$ são equivalentes, ou seja, um pode simular o outro. 
Demonstração. Como $N$ sempre é ímpar, $2 x \bmod N$ é par se, e somente se, $x<N / 2$. Portanto, $\mathcal{O}_{1}(\operatorname{RSA}(2 x))=0$ se, e somente se, $\mathcal{O}_{2}(\operatorname{RSA}(x))=0$. Isso mostra que o oráculo $\mathcal{O}_{1}$ pode simular $\mathcal{O}_{2}$. No sentido contrário, seja $y \equiv x^{e} \bmod N$ e seja $I \equiv 2^{-e} \bmod N$, então $\mathcal{O}_{1}(y)=0$ se, e somente se, $\mathcal{O}_{2}(I y)=0$. Isso mostra que o oráculo $\mathcal{O}_{2}$ também pode ser usado para simular o oráculo $\mathcal{O}_{1}$.

Essa discussão sobre oráculos, sejam eles para o LSB, para a paridade ou para as duas metades do conjunto, nos leva a imaginar uma variedade de outros oráculos possíveis. Quando na Seção 1.2 de objetivos (pág. 4) nós vislumbramos a possibilidade de utilizar uma informação obtida por canal secundário, imaginávamos como uma implementação ruim poderia se encaixar dentro de um determinado tipo de oráculo.

Como exemplo de implementação inadequada, podemos citar o algoritmo de exponenciação modular citado por Terada no Apêndice C.18 de seu livro [Ter08]. Trata-se um algoritmo rápido e bastante simples, mas é sensível ao bits da chave, oferecendo a possibilidade de ataque por tempo.

Então, tendo em mente esses fatos, citamos algumas variedades de oráculos que podem ser utilizados em ataques. Esses exemplos foram extraídos de [GMT82] e de [BOCS83]:

- para um RSA de $n$ bits, com $k$ tal que $0 \leq k<n$, onde o módulo $N$ tem seus últimos $k$ LSBs iguais a 1 , um oráculo que determina o $(k+1)$-ésimo bit da mensagem $x$ pode ser usado;

- para um intervalo $D$ de tamanho não negligenciável $\varepsilon<\frac{|D|}{N}<1-\varepsilon$, um oráculo que determina se $x \in D$ pode ser usado;

- um oráculo, onde dada a mensagem encriptada $\operatorname{RSA}(x)$, determina a paridade do $(k)$-ésimo bit da mensagem $x$ pode ser usado;

- um oráculo, onde dada a mensagem encriptada $\operatorname{RSA}(x)$, determina o LSB da mensagem $x$ com probabilidade maior que $\frac{1}{2}+\frac{1}{4}$ pode ser usado.

Além desses, os artigos detalham outros para o algoritmo Rabin.

\subsection{Máximo divisor comum}

O máximo divisor comum (MDC, também GCD do inglês Greatest Common Divisor) é um algoritmo que retorna o maior divisor comum entre dois operandos. Ele é utilizado também para verificar se dois operandos $b$ e $c$ são primos entre si, ou seja, se $\operatorname{MDC}(b, c)=1$.

Além da especificação padrão do algoritmo, em alguns métodos desta dissertação utilizamos os conceitos de uma versão chamada MDC binário baseado em Knuth [Knu81, Sec.4.5.2 Alg.B p.321]. Nela são utilizadas as seguintes propriedades devidas a Stein [Ste67]:

- se $|b|$ e $|c|$ são ambos pares, então $\operatorname{MDC}(b, c)=2 \cdot \operatorname{MDC}\left(\frac{b}{2}, \frac{c}{2}\right)$;

- se $|b|$ é par e $|c|$ ímpar, então $\operatorname{MDC}(b, c)=\operatorname{MDC}\left(\frac{b}{2}, c\right)$; 
- se $|b|$ e $|c|$ são ambos ímpares, então $\operatorname{MDC}(b, c)=2 \cdot \operatorname{MDC}\left(\frac{b+c}{2}, \frac{b-c}{2}\right)$;

- adicionalmente, no último caso, ou $\frac{b+c}{2}$ ou $\frac{b-c}{2}$ é divisível novamente por 2 .

Essas propriedades foram utilizadas para se criar um MDC binário modificado em [BOCS83] e no Brent Kung GCD [BK84] utilizado no ACGS.

\subsection{Desigualdade de Chebyshev}

A Desigualdade de Chebyshev é uma ferramenta estatística que nos permite estabelecer limitantes para uma distribuição de probabilidade que não conhecemos. Sua importância vem do fato de só necessitar o conhecimento da esperança e da variância da distribuição. Ela é estabelecida no Teorema 2.10.1.

Notação. A esperança, também chamada de meio, expectância ou valor esperado, é uma medida que representa o valor médio esperado de uma experiência repetida muitas vezes e é denotada por $\mu$ ou por $\operatorname{Exp}[X]$ no caso da variável aleatória $\mathrm{X}$.

Notação. A variância é uma medida que indica o quão longe em geral os valores de uma experiência podem estar do valor esperado e é denotada por $\sigma^{2}$ ou por $\operatorname{Var}[X]$ no caso da variável aleatória X.

Teorema 2.10.1 (Desigualdade de Chebyshev). [Ros06, Prop.8.2.2] Seja X uma variável aleatória com meio finito $\mu$ e variância $\sigma^{2}$, então para qualquer valor $k>0$,

$$
\operatorname{Pr}(|X-\mu| \geq k) \leq \frac{\sigma^{2}}{k^{2}}
$$

Agora, vamos ver dois exemplos de aplicação do Teorema 2.10.1 - obtido do livro de Ross [Ros06, Example 8.8b].

Exemplo 2.10.2 (Distribuição uniforme). Seja $X$ uma variável aleatória distribuída uniformemente no intervalo $(\alpha, \beta)$, então considerando o intervalo $(0,10)$ temos $\operatorname{Exp}[X]=\frac{\beta+\alpha}{2}=5$ e $\operatorname{Var}[X]=$ $\frac{(\beta-\alpha)^{2}}{12}=\frac{100}{12}=\frac{25}{3}$; segue da Desigualdade Chebyshev que

$$
\operatorname{Pr}(|X-5|>4) \leq \frac{25}{3(16)} \approx 0,52
$$

enquanto que o valor exato seria

$$
\operatorname{Pr}(|X-5|>4)=\operatorname{Pr}(X<1)+\operatorname{Pr}(X>9)=\frac{2}{10}=0,2
$$


Exemplo 2.10.3 (Distribuição normal). Seja $X$ uma variável aleatória de distribuição normal com meio $\mu$ e variância $\sigma^{2}$, a Desigualdade Chebyshev estabelece que

$$
\operatorname{Pr}(|X-\mu|>2 \sigma) \leq \frac{\sigma^{2}}{(2 \sigma)^{2}}=\frac{1}{4}
$$

onde a probabilidade seria melhor dada por

$$
\begin{aligned}
\operatorname{Pr}(|X-\mu|>2 \sigma) & =\operatorname{Pr}\left(\left|\frac{X-\mu}{\sigma}\right|>2\right) \\
& =\operatorname{Pr}(|Z|>2) \\
& =\operatorname{Pr}(|Z| \leq-2) \\
& =2 \operatorname{Pr}(Z \leq-2) \\
& =2 \Phi(-2) \\
& =2[1-\Phi(2)] \\
& \approx 2[1-0,9772] \\
& \approx 0,0456
\end{aligned}
$$

Aqui, fizemos a substituição de $\frac{X-\mu}{\sigma}$ pela variável aleatória normal padrão $Z$, usamos o valor $\Phi(2)=0,9772$ da tabela normal padrão e aplicamos algumas outras identidades (q.v. [Ros06, Sec.5.4]).

Do Exemplo 2.10 .2 observamos uma disparidade de $52 \%$ para 20\%. Já no Exemplo 2.10.3 a diferença foi de $25 \%$ para 4,5\%. Então, apesar do Teorema 2.10.1 nos fornecer uma ferramenta poderosa que consegue aproximar uma distribuição de probabilidade desconhecida, ela pode estabelecer limitantes não muito restritos na prática, muitas vezes, bem distantes da probabilidade real.

A Desigualdade Chebyshev frequentemente é utilizada como ferramenta teórica para provar resultados. Ela está sendo utilizada para provar a convergência do algoritmo ACGS na Seção 3.1 (pág. 25). Com base em nossa discussão sobre a acurácia do limitante de probabilidade, acreditamos que nesse ponto poderia estar uma fonte de superestimação dos erros. De fato, isso se confirmou nos resultados finais obtidos.

Enfim, acabamos de revisar os fundamentos de álgebra, curvas, complexidade computacional, criptografia, nível de segurança, números aleatórios, oráculos, MDC e probabilidade. De posse desses conceitos podemos passar agora para o Capítulo 3 de metodologia e implementação. Nesse capítulo, a seguir, veremos a aplicação dos conceitos aqui estudados. 


\section{Capítulo 3}

\section{Métodos e Implementação}

Nesta dissertação, trabalhamos com dois criptossistemas, o RSA e o DHCE. Neste capítulo, vamos apresentar métodos que se utilizam de um oráculo para tentar inverter esses criptossistemas. Ainda, daremos detalhes das implementações de tais métodos.

Dividimos esse capítulo conforme: na Seção 3.1. apresentamos os algoritmos para inversão do RSA; na Seção 3.2, apresentamos os algoritmos para inversão do DHCE; na Seção 3.3. falamos da ferramenta utilizada para implementação.

\subsection{Algoritmos para o RSA}

O algoritmo ACGS para o RSA remonta em diversos trabalhos precursores que vamos discutir agora. Entretanto, vamos primeiro definir a segurança do LSB para o RSA - sempre que falarmos de LSB no RSA, nos referimos ao LSB da mensagem original, não conhecida.

Definição 3.1.1. Seja $\mathcal{O}_{N}$ um oráculo para o LSB do $\operatorname{RSA}$, tal que $\operatorname{Adv}\left(\mathcal{O}_{N}\right)=\varepsilon>0$, e temos o conhecimento de um algoritmo que é capaz de utilizar $\mathcal{O}_{N}$ para inverter o RSA. Então dizemos que nesse caso o LSB é $(\varepsilon)$-seguro.

Definição 3.1.2. Dizemos que o LSB é imprevisível se ele é $\left(n^{-c}\right)$-seguro, para toda contante constante $c>0$.

O nome imprevisivel na Definição 3.1.2 é escolhido assim devido ao fato de não acreditarmos na existência de $\mathcal{O}_{N}$.

Em GMT82 foi provado que o LSB era $\left(\frac{1}{2}-\frac{1}{n}\right)$-seguro. Já em [BOCS83] foi provado que o LSB era $\left(\frac{1}{4}\right)$-seguro, ou seja, com um oráculo falho que errava em $25 \%$ das consultas. Nesse trabalho, os autores utilizaram uma técnica de medidas sucessivas que conseguia construir uma função de paridade para o LSB com probabilidade de acerto quase perfeita. Em contrapartida, tal técnica limitava o erro do oráculo a $25 \%$, esse problema foi chamado de duplicação dos erros (error doubling). 
Em 1983, Vazirani e Vazirani [VV83 mostraram uma nova técnica de amostragem tentando contornar o problema de duplicação dos erros. Porém, o ganho foi mínimo, provando apenas que o LSB era (0,232)-seguro.

O problema com a duplicação dos erros é que a cada amostra são feitas duas consultas ao oráculo. Somente em [ACGS88] com o algoritmo ACGS esse problema foi contornado. Agora, apenas uma consulta é feita por amostra. Com isso, é possível o uso de oráculos com vantagens bem pequenas. O ACGS provou que o LSB é imprevisível, ou seja, $\left(\frac{1}{\text { poli }(n)}\right)$-seguro.

Em nossa opinião, a grande contribuição do ACGS foi a criação de uma nova metodologia de amostragem capaz de contornar o problema da duplicação dos erros. Na ocasião, um dos autores, Chor, teve sua tese premiada e uma publicação especial em [Cho86] (An ACM Distinguished Dissertation 1985).

A partir deste ponto na seção, vamos supor a existência de um oráculo $\mathcal{O}_{N}$ com vantagem $\varepsilon$ em descobrir o LSB do RSA com módulo $N$. Onde a vantagem $0<\varepsilon \leq \frac{1}{2}$ é pequena, porém não negligenciável (q.v. Seção 2.8, pág. 21). Vamos mostrar como o ACGS faz uso de $\mathcal{O}_{N}$ para inverter o RSA.

Um primeiro passo antes de executar o algoritmo, é sempre verificar se a mensagem $x$ é coprima $\operatorname{com} N$. Caso não seja, teremos $\operatorname{MDC}(x, N)=z$, onde, ou $z \equiv N \equiv 0(\bmod N)$, ou $z$ é igual a um dos fatores primos $q_{1}$ ou $q_{2}$ de $N$. Embora pareça só uma questão de eficiência (pois quebramos todo o sistema), essa verificação é obrigatória, sem ela a implementação é capaz de entrar em um estado de laço de repetição infinito.

Notação. Para facilitar a escrita, seja $x$ um inteiro, denotamos $[x]_{N}$ como o resto de $x$ módulo N, ou seja, $[x]_{N}=x \bmod N$.

Em determinada parte do algoritmo teremos uma mensagem $x$ e serão escolhidos dois números aleatórios $a$ e $b$, desejamos que os produtos $[a x]_{N}$ e $[b x]_{N}$ sejam "pequenos". Aqui, pequeno quer dizer $[a x]_{N}<\frac{\varepsilon}{2} N$, isto é, $[a x]_{N}$ está bem próximo de 0 . Também, é interessante um $[a x]_{N}$ pequeno que esteja bem próximo de $N$, ou seja, do outro lado de 0 . Descrevemos formalmente essa noção com uso da definição a seguir.

Definição 3.1.3. Seja $x$ um inteiro, definimos

$$
\operatorname{abs}_{N}(x) \stackrel{\text { def }}{=} \begin{cases}{[x]_{N}} & \text { se }[x]_{N}<N / 2 \\ N-[x]_{N} & \text { caso contrário }\end{cases}
$$

Desse modo, dizemos $[a x]_{N}$ pequeno se $\operatorname{abs}_{N}(a x)<\frac{\varepsilon}{2} N$.

De acordo com a propriedade multiplicativa do RSA (q.v. final da Seção 2.4 pág. 14), mesmo sem conhecer o valor de $x$ é possível calcular RSA $(a x)$. Para isso, dado $a$ e a mensagem encriptada $\operatorname{RSA}(x)$, calculamos $\operatorname{RSA}(a)$ e fazemos $\operatorname{RSA}(a) \cdot \operatorname{RSA}(x)=a^{e} x^{e} \bmod N=R S A(a x)$. Do mesmo modo, dado $\operatorname{RSA}(a x)$, podemos calcular $\operatorname{RSA}\left(2^{-1} a x\right)$. 
Se dado RSA $(a x)$ podemos calcular a divisão por 2 e ainda calcular a paridade de $[a x]_{N}$ através do oráculo $\mathcal{O}_{N}$; então somos capazes de construir um algoritmo para o MDC binário nos moldes das regras estabelecidas na Seção 2.9 (pág. 222). Isso tudo significa que conseguimos calcular $\operatorname{MDC}(\operatorname{RSA}(a x), \operatorname{RSA}(b x))=\operatorname{RSA}(\ell x)$ e ao final, teremos conhecimento do valor de $[\ell]_{N}$ e de $\operatorname{RSA}(\ell x)$, embora não o de $[\ell x]_{N}$.

Agora se $[a x]_{N}$ e $[b x]_{N}$ são primos entre si, então $\operatorname{MDC}\left([a x]_{N},[b x]_{N}\right)=1$. Note que sempre temos $R S A(1)=1$. Assim, se $\operatorname{MDC}\left([a x]_{N},[b x]_{N}\right)=1$, então também $\operatorname{MDC}(\operatorname{RSA}(a x), \operatorname{RSA}(b x))=$ $\operatorname{RSA}(\ell x)=1$. Disso resulta que $[\ell x]_{N}=1$, portanto é fácil recuperar $x$ com o cômputo do inverso de $\ell$, isto é, $x \equiv \ell^{-1}(\bmod N)$.

Em [BOCS83. os autores criaram um MDC binário modificado baseado nas regras da Seção 2.9 (pág. 22). Já no ACGS, os autores decidiram utilizar um MDC baseado no trabalho de Brent e Kung [BK84, Sec.6.1] que é mais eficiente. Vamos chamar esse algoritmo de BKGCD.

Com base nessas propriedades, descrevemos o ACGS no Algoritmo 3.1 para inverter o RSA.

Ao chegar na Parte 3 do algoritmo, a variável $a$ contém um valor cujo produto com $x$ é o MDC de $[a x]_{N}$ e $[b x]_{N}$. É neste momento que precisamos que $[a x]_{N}$ e $[b x]_{N}$ sejam coprimos, pois na verificação da Linha 27 teremos $\operatorname{RSA}(a x)= \pm 1$ e assim conseguimos recuperar $x$ através do cálculo do inverso multiplicativo $\left[ \pm a^{-1}\right]_{N}$. Caso não sejam coprimos, o algoritmo volta para Linha $2 \mathrm{e}$ sorteia novamente $a$ e $b$ na esperança que esses valores resultem em $[a x]_{N}$ e $[b x]_{N}$ coprimos.

Por um famoso teorema de Dirichlet [Knu81, Sec.4.5.2 Theo.D p.324], a probabilidade de dois inteiros aleatórios no intervalo $[-K, K]$ serem relativamente primos converge para $\frac{6}{\pi^{2}}$ conforme $K$ tende a $\infty$. Isso é algo em torno de 60,8\%. Assim, com duas tentativas em $a$ e $b$ já é esperado encontrar coprimos em $[a x]_{N},[b x]_{N}$.

Outras condições que fazem o algoritmo retornar à Linha 2 se referem à variável limiteGCD, que chamaremos limitante do BKGCD. Esse limitante é para o caso quando a função PAR é falha, assim o algoritmo não ficará executando eternamente. A função PAR é uma função de paridade, por exemplo, dado $\operatorname{PAR}(b, y)$, ela retorna a paridade de $[b x]_{N}$.

A função BKGCD originalmente exige que a entrada $[a x]_{N}$ seja ímpar. Essa condição não apareceu na descrição do algoritmo em [ACGS88. Então garantimos isso adicionando o laço de repetição entre as Linhas [6 e 10. O tempo de execução máximo do BKGCD original é de $2 n+1$. Já no ACGS, estamos interessados em limitar a quantidade máxima de chamadas à função PAR, por isso o limitante do BKGCD foi estabelecido igual a $6 n+3$.

Vamos agora descrever a função de paridade PAR. Ela é apresentada no Algoritmo 3.2.

A função PAR faz uma quantidade $m$ de amostras entorno da paridade de $d x$, denominadas medidas-dx. São somados os votos para a resposta, par ou ímpar, nas variáveis contador 0 e contador $_{1}$. O resultado é a maioria dos votos.

Perceba que para cada medida, não bastaria simplesmente consultar $\mathcal{O}_{N}(\operatorname{RSA}(d x))$ para os votos, isso porque consideramos o oráculo $\mathcal{O}_{N}$ como um algoritmo determinístico.

Assim, cada voto de paridade é obtido verificando se $\operatorname{LSB}(r x)=\operatorname{LSB}(r x+d x)$. A igualdade se mantém se, e somente se, $d x$ for par, isso porque um número par não altera a paridade de outro número na operação de soma. O problema aqui é se na adição $r x+d x$ ocorrer uma redução modular 


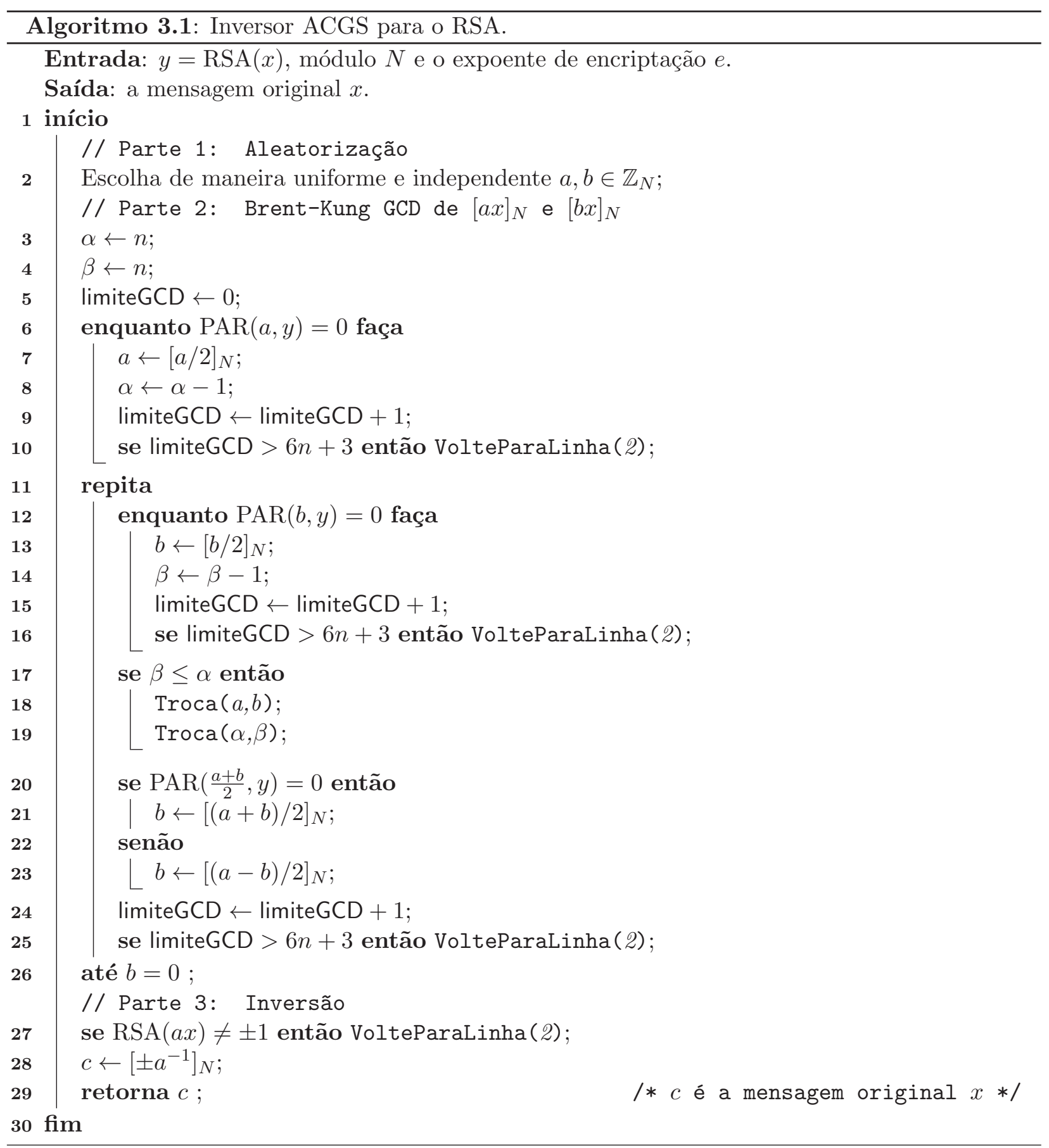




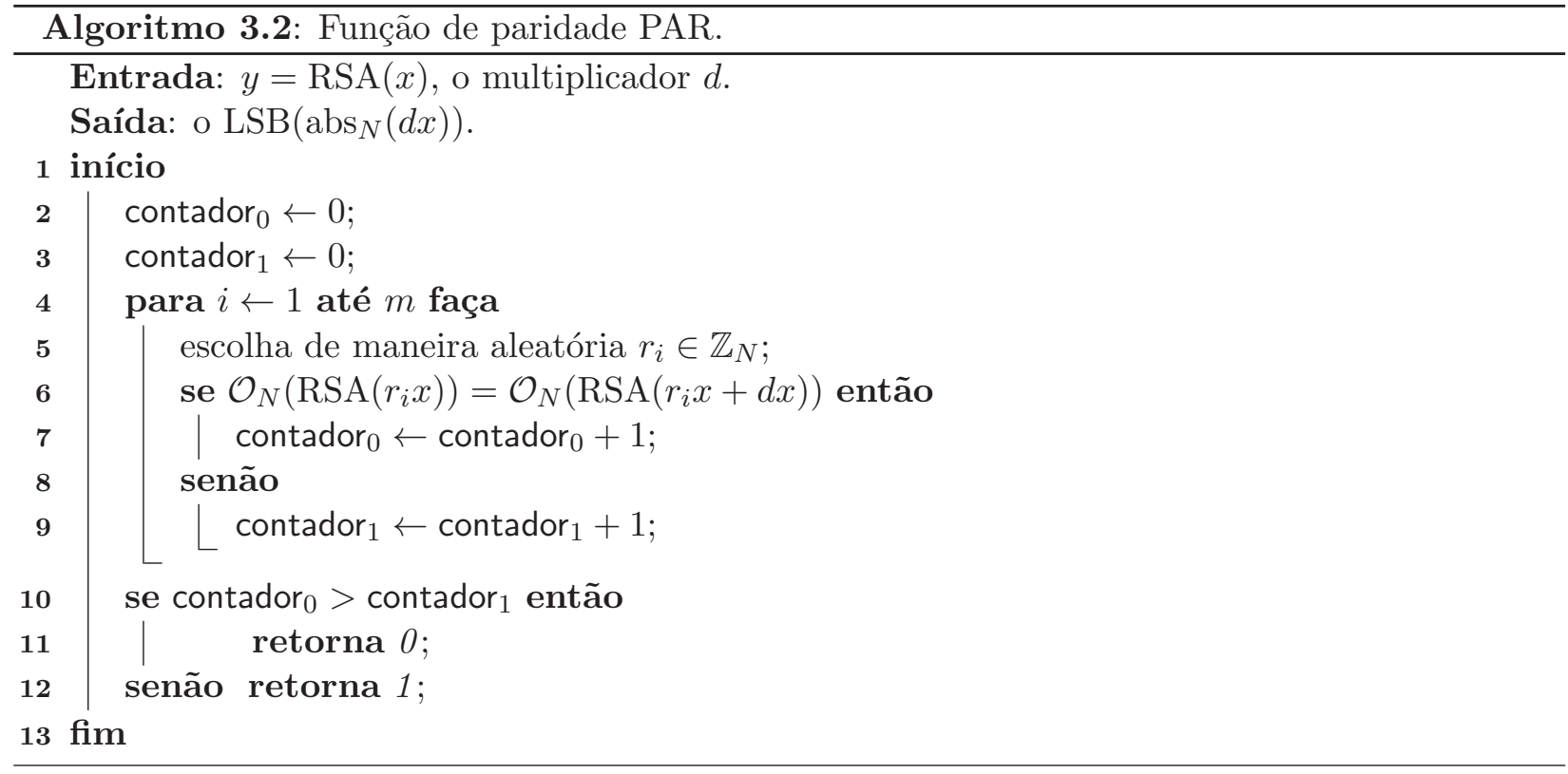

(também chamada overlapping ou wraparound). Como $N$ é ímpar, o voto é invertido. Aqui está a necessidade de que $[a x]_{N}$ e $[b x]_{N}$ sejam pequenos, pois teremos $[d x]_{N}$ pequeno e na adição $r x+d x$ a probabilidade de redução modular ocorrer também será pequena $\left(\frac{\varepsilon}{2}\right)$. Note que conforme a função BKGCD evolui, os valores $[a x]_{N}$ e $[b x]_{N}$ intermediários continuam pequenos e vão diminuindo ainda mais.

O fato da função PAR retornar o LSB de $\operatorname{abs}_{N}(d x)$, ou seja, com a função abs ${ }_{N}$, faz parte da estrutura da função PAR. Na adição $r x+d x$, se $d x$ estiver próximo de $N$, a operação seria como uma subtração: $[r x]_{N}+[d x]_{N}=[r x]_{N}+N-\operatorname{abs}_{N}(d x)=r x-\operatorname{abs}_{N}(d x) \bmod N$. A análise dá margem à investigação de várias possibilidades. Porém, deixando de lado detalhes aritméticos, o que se torna importante no momento da implementação do ACGS é o que se vê na Linha 27 do Algoritmo 3.1. Nessa linha a comparação é feita com \pm 1 . Nesse caso, -1 pode representar $N-1$, e a variável $a$ retornada pelo BKGCD deve ser modificada para $a \leftarrow N-a$ antes do cálculo do inverso multiplicativo, de modo que só assim teremos $c=x$.

Com esse esquema de votos, conseguimos construir uma função de paridade quase perfeita, desde que a quantidade de medidas $m$ seja grande o suficiente. Isso é garantido pela lei dos grandes números.

Voltando ao Algoritmo 3.2. para cada medida na Linha6, são feitas duas consultas ao oráculos. A maneira como PAR está aqui escrita é a que foi estabelecida em [BOCS83, o que provoca o problema de duplicação dos erros. Se o oráculo errar em mais de $25 \%$ dos casos, as duas probabilidades de erros somadas chegariam a $50 \%$ e anularia a convergência da função de paridade.

No trabalho de ACGS88, o ACGS altera a Linha 6 de modo que o oráculo só é consultado do lado direito da igualdade $(r x+d x)$. Quanto ao lado esquerdo $(r x)$, o LSB de $r x$ já é conhecido. Isso é possível dividindo o conjunto dos inteiros módulo $\mathrm{N}$ em intervalos e aplicado uma técnica de 
suposição que vamos explanar os passos a seguir:

- escolha de maneira uniforme e independente $k, l \in \mathbb{Z}_{N}$;

- computamos $m$ valores $\left[r_{i} x\right]_{N}$ de modo que $\left[r_{i} x\right]_{N}=[(k+i l) x]_{N}, \operatorname{com} i=1,2, \ldots, m$;

- se chamarmos $y=[k x]_{N}$ e $z=[l x]_{N}$, então $\left[r_{i} x\right]_{N} \equiv y+i z \bmod N$;

- suponha que conhecemos a localização de $y$ dentro de um dos $4 \varepsilon^{-1}$ intervalos

$$
\left[j \frac{\varepsilon N}{4},(j+1) \frac{\varepsilon N}{4}\right], \quad 0 \leq j<\frac{4}{\varepsilon}
$$

- suponha que conhecemos a localização de $z$ dentro de um dos $4 m \varepsilon^{-1}$ intervalos

$$
\left[j \frac{\varepsilon N}{4 m},(j+1) \frac{\varepsilon N}{4 m}\right], \quad 0 \leq j<\frac{4 m}{\varepsilon}
$$

- suponha que conhecemos $\operatorname{LSB}(y)$ e $\operatorname{LSB}(z)$;

- com o conhecimento da localização nos intervalos e do LSB de $y$ e $z$ é fácil calcular $\operatorname{LSB}\left(r_{i} x\right)$.

Note que das suposições, temos ao todo $2 \cdot 4 \varepsilon^{-1} \cdot 2 \cdot 4 m \varepsilon^{-1}=2^{6} m \varepsilon^{-2}$ possibilidades. Rodamos o ACGS com cada uma dessas alternativas. Em apenas uma delas estaremos computando corretamente $\operatorname{LSB}\left(r_{i} x\right)$ e chamaremos essa instância de alternativa correta. Então, na alternativa correta o ACGS recupera a mensagem original.

Sobre o cálculo de $\operatorname{LSB}\left(r_{i} x\right)$, definimos $w_{i} \stackrel{\text { def }}{=} y+i z$ e, para cada $i$, vamos computando os LSBs seguindo a regra $\operatorname{LSB}\left(w_{i}\right) \leftarrow \operatorname{LSB}(y)+i \operatorname{LSB}(z) \bmod 2$. Ademais, calculamos o quociente inteiro $\frac{w_{i}}{N}$, e caso seja ímpar, invertemos o valor do $\operatorname{LSB}\left(w_{i}\right)$ computado antes. Observe que mesmo não conhecendo exatamente o valor $w_{i}$, isso não nos impede de descobrir $\operatorname{LSB}\left(w_{i}\right)$.

$\mathrm{Na}$ verdade, conhecemos a localização - apenas aproximada - de $y$ dentro de um intervalo de tamanho $\frac{\varepsilon N}{4}$. A localização de $z$ é conhecida dentro de um intervalo também de tamanho no máximo $\frac{\varepsilon N}{4}$, devido ao fato que quando $i=0$ o intervalo é menor e de tamanho $\frac{\varepsilon N}{4 m}$, mas a medida que $i$ cresce o intervalo aumenta até $\frac{\varepsilon N}{4}$. Assim, conhecemos a localização aproximada de $w_{i}$ dentro de um intervalo de tamanho no máximo $\frac{\varepsilon N}{4 m}+\frac{\varepsilon N}{4 m}=\frac{\varepsilon N}{2}$.

Quando $w_{i}$ cai em um intervalo contendo um múltiplo de $N$ há uma ambiguidade. Não sabemos dizer se o quociente inteiro $\frac{w_{i}}{N}$ é par ou ímpar. Como o tamanho desse intervalo é de $\frac{\varepsilon N}{2}$, a probabilidade desse caso ocorrer é igual a $\frac{\varepsilon}{2}$. Para resolver esta ambiguidade, arbitrariamente consideramos que $w_{i}$ cai na parte mais alta do intervalo e assim ocorre uma redução modular adicional para $\left[w_{i}\right]_{N}$. Então a probabilidade de errar o LSB de $r_{i} x$ cai para $\frac{\varepsilon}{4}$.

Na Seção 4.1 de ACGS88 os autores demonstram as seguintes propriedades a respeito dos valores $r_{i} x$ gerados:

1. cada valor $r_{i} x$ é uniformemente distribuído em $\mathbb{Z}_{N}$; 
2. os valores são par a par independentes;

3. o LSB de cada valor é conhecido com probabilidade $\geq 1-\frac{\varepsilon}{4}$.

Agora passemos para a análise de erro. Cada medida-dx na amostragem da função PAR tem três fontes de erro:

1. o oráculo erra na consulta do LSB de $\left[r_{i} x+d x\right]_{N}$;

2. uma redução módulo $N$ ocorre quando $\left[r_{i} x\right]_{N}$ é adicionado a $[d x]_{N}$;

3. o LSB pré-computado de $\left[r_{i} x\right]_{N}$ está errado.

Ignorando as intersecções de probabilidade, somamos todos os erros, respectivamente: $\left(\frac{1}{2}-\varepsilon\right)+$ $\left(\frac{\varepsilon}{2}\right)+\left(\frac{\varepsilon}{4}\right)=\frac{1}{2}-\frac{\varepsilon}{4}$.

Definimos a variável aleatória de erro:

$$
\zeta_{i}= \begin{cases}1 & \text { se a } i \text {-ésima medida-dx estiver errada } \\ 0 & \text { se a } i \text {-ésima medida-dx estiver correta }\end{cases}
$$

Temos que $\operatorname{Exp}\left(\zeta_{i}\right)=\operatorname{Pr}\left(\zeta_{i}=1\right)<\frac{1}{2}-\frac{\varepsilon}{4}$ e calculamos $\operatorname{Var}\left(\zeta_{i}\right)<\frac{1}{4}$. Então, a probabilidade de erro da função PAR é definida por:

$$
\operatorname{Pr}(\mathrm{PAR} \text { errar })=\operatorname{Pr}\left(\frac{1}{m} \sum_{i=1}^{m} \zeta_{i} \geq \frac{1}{2}\right)
$$

Ao subtrair $\operatorname{Exp}\left(\zeta_{i}\right)$ de cada lado da inequação, podemos aplicar a Desigualdade de Chebyshev:

$$
\operatorname{Pr}\left(\frac{1}{m} \sum_{i=1}^{m} \zeta_{i} \geq \frac{1}{2}\right) \leq \operatorname{Pr}\left(\left|\frac{1}{m} \sum_{i=1}^{m} \zeta_{i}-\operatorname{Exp}\left(\zeta_{i}\right)\right| \geq \frac{\varepsilon}{4}\right) \leq \frac{\operatorname{Var}\left(\frac{1}{m} \sum_{i=1}^{m} \zeta_{i}\right)}{\left(\frac{\varepsilon}{4}\right)^{2}}
$$

As variáveis $\zeta_{i}$ são par a par independentes devido ao modo como os valores $r_{i} x$ são gerados. Isso implica que $\operatorname{Var}\left(\sum_{i=1}^{m} \zeta_{i}\right)=\sum_{i=1}^{m} \operatorname{Var}\left(\zeta_{i}\right)$ [Ros06, Sec.7.4 Eq.4.1]. Desenvolvendo temos:

$$
\begin{aligned}
\operatorname{Pr}(\text { PAR errar }) & \leq \frac{\frac{1}{m^{2}} \operatorname{Var}\left(\sum_{i=1}^{m} \zeta_{i}\right)}{4^{-2} \varepsilon^{2}} \\
& =\frac{\frac{1}{m^{2}} \sum_{i=1}^{m} \operatorname{Var}\left(\zeta_{i}\right)}{4^{-2} \varepsilon^{2}} \\
& =\frac{\frac{1}{m^{2}} m \operatorname{Var}\left(\zeta_{i}\right)}{4^{-2} \varepsilon^{2}} \\
& \leq \frac{\frac{1}{m^{2}} m \frac{1}{4}}{4^{-2} \varepsilon^{2}} \\
& =\frac{4}{m \varepsilon^{2}}
\end{aligned}
$$


Então temos que escolher uma amostragem $m$ suficientemente grande para que tenhamos uma função de paridade quase perfeita. Os autores escolheram em [ACGS88, um valor de $m \stackrel{\text { def }}{=} 64 n \varepsilon^{-2}$. Calculando:

$$
\operatorname{Pr}_{m=64 n \varepsilon^{-2}}(\operatorname{PAR} \text { errar }) \leq \frac{4}{\left(64 n \varepsilon^{-2}\right) \varepsilon^{2}}=\frac{1}{16 n}
$$

Com probabilidade de erro $\frac{1}{16 n}$, a função PAR, em média, consegue passar sem erro em todas as requisições da função BKGCD (no máximo limite $G C D=6 n+3$ chamadas).

De acordo com a nossa discussão sobre a Desigualdade de Chebyshev na Seção 2.10 (pág. 23), acreditamos que a probabilidade de erro da função PAR é superestimada aqui, ainda mais que para o cálculo de $\operatorname{Exp}\left(\zeta_{i}\right)$ não foram consideradas as intersecções das probabilidades de erros das medidas-dx.

Veremos como isso se confirma no Capítulo 4 de resultados (pág. 391). Veremos também, empiricamente, que na média o limitante do BKGCD pode ser menor do que $6 \mathrm{n}+3$, pelo menos metade.

Note que ao final do ACGS teremos uma lista de candidatos $c$ para a mensagem $x$ correspondendo a cada uma das alternativas. Podemos identificar o candidato $c$ correto comparando se $R S A(c)$ é igual a $y=x^{e} \bmod N$. Assim, em vez de esperar o final do algoritmo, ao sabermos que chegamos na alternativa correta, as demais execuções de alternativas podem ser descartadas.

O tempo de execução do ACGS corresponde a $\varepsilon^{-2}$ tentativas para se obter $a x$ e $b x$ pequenos, mais duas tentativas para que sejam coprimos $\left(\frac{\pi^{2}}{6}\right)$, mais a execução das $2^{6} m \varepsilon^{-2}$ alternativas, $6 n+3$ chamadas à função PAR e $m$ medidas-dx. Escrevendo tudo:

$$
\varepsilon^{-2} \cdot 2 \cdot 2^{6} m \varepsilon^{-2} \cdot(6 n+3) \cdot m \approx 3 \cdot 2^{8} \varepsilon^{-4} n m^{2} \approx 3 \cdot 2^{8} \varepsilon^{-4} n\left(\frac{64 n}{\varepsilon^{2}}\right)^{2} \approx 3 \cdot 2^{20} \varepsilon^{-8} n^{3}=O\left(\varepsilon^{-8} n^{3}\right)
$$

Abriremos uma seção breve, a seguir, para discutir o algoritmo FS, também para o RSA.

\subsubsection{Sobre o algoritmo FS para o RSA}

No trabalho de FS, em vez de utilizar uma função de MDC como o de Brent e Kung, os autores retornaram a utilizar um método de divisão binária inicialmente utilizada em [GMT82. Porém aqui, diferente de [GMT82], o oráculo é falho com $\operatorname{Adv}\left(\mathcal{O}_{N}\right)=\varepsilon$.

Do mesmo modo como no ACGS, fazemos apenas uma consulta ao oráculo por medida-dx com ajuda da técnica de suposição. Com isso, temos que considerar novamente uma determinada quantidade de alternativas.

$\mathrm{Na}$ alternativa correta, escolhido um aleatório $a$, o valor inicial de $a_{0} x$ é suposto estar em um intervalo $I$, o tamanho do intervalo $|I|$ é dividido por 2 sucessivamente até o ponto em que $|I|<\frac{1}{2}$ e ao final teremos $a_{n} x$. Tomamos também um $u$ inicial que é uma aproximação para $a x$, tal que $u_{0} \in I$. Do mesmo modo, ao final temos $|I|<\frac{1}{2}$ e $u_{n} \in I$, consequentemente esperamos $a_{n} x \approx u_{n}$. Calculamos a resposta $c \equiv a_{n}^{-1}\left\lfloor u_{n}+\frac{1}{2}\right\rfloor \bmod N$; note que $\left\lfloor u_{n}+\frac{1}{2}\right\rfloor=a_{n} x$.

O tempo esperado do algoritmo é de $3 \cdot 2^{9} \varepsilon^{-6} n^{2}$. Essa é a primeira versão do algoritmo e vamos chamá-la FS 1. 
Após alguma melhorias no modo em como o oráculo é utilizado, o tempo cai para $9 \cdot 2^{8} \varepsilon^{-6} n \lg n$. Vamos chamar essa segunda versão do algoritmo de FS 2.

Embora não vamos utilizar o seu tempo aqui, existe uma terceira versão que consegue, a cada consulta ao oráculo, calcular simultaneamente apenas uma medida-dx para todas as alternativas [FS00, Sec.4]. Essa versão utiliza Transformada Rápida de Fourier e consegue diminuir um prejuízo no tempo causado por um oráculo demorado.

Adicionalmente, utilizando conceitos de teoria da informação, os autores provaram que para inverter o RSA seriam necessárias pelo menos $\frac{\ln 2}{4} n \varepsilon^{-2}$ consultas ao oráculo [FS00, Theo.3].

Enquanto no ACGS são feitas $(6 n+3) m=(6 n+3) \frac{64 n}{\varepsilon^{2}} \approx 10 n^{2} \varepsilon^{-2}$ consultas ao oráculo, no FS 2 são feitas $9 n \lg n \varepsilon^{-2}$. No Capítulo 4 de resultados (pág. 39), nossas modificações no ACGS reduziram o número de consultas para apenas $12 n \varepsilon^{-2}$, aproximando-nos ainda mais do número ótimo de consultas.

\subsection{Algoritmos para o DHCE}

O algoritmo BS faz uma adaptação do algoritmo ACGS (embora também seja possível utilizar o FS) para uso no DHCE. Os autores utilizaram curvas primas.

Considere um grupo cíclico de curva prima $E\left(\mathbb{F}_{p}\right)$ com um gerador $G$ de ordem prima $q$, e as chaves privadas de Alice e Beto $a, b \in[1, q-1]$, definimos o segredo da função Diffie-Hellman

$$
D H_{E, G}(a G, b G)=a b G
$$

como a coordenada $x$ do ponto $a b G$. Nessa seção, supomos a existência de um oráculo $\mathcal{O}_{p}$ para $[a b G]_{x}$, tal que $\operatorname{Adv}_{E, G}^{X}\left(\mathcal{O}_{p}\right)=\varepsilon$.

Para um $\lambda \in \mathbb{F}_{p}^{*}, \phi_{\lambda}(E)$ define a curva elíptica

$$
Y^{2}=X^{3}+A \lambda^{4} X+B \lambda^{6}
$$

os autores chamam-na twisted elliptic curve. De acordo com a Seção 2.2 (pág. 10), é fácil identificar que esses twists são na verdade isomorfismos. Assim, para pontos $Q, R, S, \in E$, com $Q=(x, y)$, temos $(Q)_{\lambda}=Q_{\lambda}=\left(\lambda^{2} x, \lambda^{3} y\right) \in \phi_{\lambda}(E)$ e para $Q+R=S$, também $Q_{\lambda}+R_{\lambda}=S_{\lambda}$ (propriedade homomórfica). Ainda, com tais twists, definimos para uma curva inicial $E_{0}$, uma família de curvas isomorfas $\phi_{\lambda}\left(E_{0}\right)_{\lambda \in \mathbb{F}_{p}^{*}}$.

Seja $K_{a b}$ o ponto combinado no DHCE sobre a curva $E_{0}$ com as chaves públicas $P K_{a}$ e $P K_{b}$. A coordenada $x$ de $K_{a b}$ é a chave secreta. Da mesma forma como no ACGS, sorteamos $a^{\prime}$ e $b^{\prime}$ (notamos $a / b$ linha para não confundir com as chaves privadas $a / b$ ) esperando que $\left[a^{\prime} x\right]_{p}$ e $\left[b^{\prime} x\right]_{p}$ sejam pequenos. Similarmente ao BKGCD, $a^{\prime}$ e $b^{\prime}$ geram valores $d$, aqui chamamos $\lambda$, e uma consulta para a paridade é feita com a chamada de $\operatorname{PAR}\left(\lambda, P K_{a}, P K_{b}\right)$. Porém, a diferença fica por conta da requisição ao LSB. A função PAR é perguntada pelo LSB de $\lambda^{2} x$, pois $\left(K_{a b}\right)_{\lambda}=\left(\lambda^{2} x, \lambda^{3} y\right)$. Então, a requisição é feita para um ponto que fica em outra curva, diferente de $E_{0}$.

Os autores consideram um oráculo $\mathcal{O}_{p}$ com vantagem $\varepsilon$ em predizer o LSB na curva $E_{0}$. Isso 


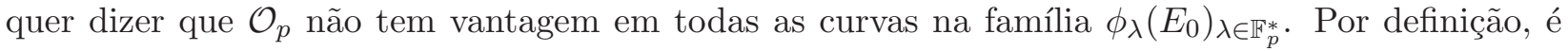
considerado que $\mathcal{O}_{p}$ mantém essa vantagem para pelo menos uma fração $\delta$ das curvas na família de isomorfismo.

O problema é que o algoritmo BS precisa consultar a paridade para vários valores de $\lambda$. Então, os autores mostram como construir um novo oráculo cuja probabilidade de sucesso dentro ou fora da fração $\delta$ das curvas seja conhecida. Vejamos o método no Lema 3.2.1.

Lema 3.2.1. BS01, Lem.1] Seja o oráculo $\mathcal{O}_{p}$ com vantagem $\operatorname{Adv}_{\phi_{\lambda}(E), \phi_{\lambda}(G)}^{X}\left(\mathcal{O}_{p}\right)=\varepsilon$ para pelo menos uma fração $\delta$ dos $\lambda \in \mathbb{F}_{p}^{*}$. Para uma entrada $\left\langle E, G, P K_{a}, P K_{b}\right\rangle$, construímos o oráculo $\mathcal{B}_{p}$ com os seguintes passos:

1. sorteamos aleatoriamente $u=\left(\frac{4}{\varepsilon \delta}\right)^{3}$ pares $a, b \in[1, q-1]$ e consultamos com $\mathcal{O}_{p}$ todas as tuplas $\langle E, G, a G, b G\rangle$;

2. seja $v$ o número de consultas para o qual $\mathcal{O}_{p}$ responde corretamente $\operatorname{LSB}\left([a b G]_{x}\right)$;

3. se $v>\frac{u}{2}$, então $\mathcal{B}_{p}$ retorna $\mathcal{O}_{p}\left(A, G, P K_{a}, P K_{b}\right)$, senão retorna o complemento desse.

Com essa construção, $\mathcal{B}_{p}$ tem $\operatorname{Adv}_{\phi_{\lambda}(E), \phi_{\lambda}(G)}^{X}\left(\mathcal{B}_{p}\right)>\frac{\varepsilon}{2}$ para uma fração $\delta$ dos $\lambda \in \mathbb{F}_{p}^{*}$; para a fração $1-\delta$ dos $\lambda$ restantes, $\mathcal{B}_{p}$ tem $\operatorname{Adv}_{\phi_{\lambda}(E), \phi_{\lambda}(G)}^{X}\left(\mathcal{B}_{p}\right)>-\frac{\varepsilon \delta}{4}$.

O oráculo $\mathcal{B}_{p}$ possui uma propriedade de interesse para o BS que é estabelecida no Lema 3.2 .2 .

Lema 3.2.2. [BS01, Lem.2] Seja o oráculo $\mathcal{B}_{p}$ do Lema [3.2.1, Então

$$
\operatorname{Pr}_{\lambda \in \mathbb{F}_{p}^{*}}\left[\mathcal{B}_{p}\left(\phi_{\lambda}(E), \phi_{\lambda}(G), \phi_{\lambda}(a G), \phi_{\lambda}(b G)\right)=\operatorname{LSB}\left(x_{\lambda}\right)\right] \geq \frac{1}{2}+\frac{\varepsilon \delta}{8}
$$

se mantém com uma probabilidade de pelo menos $\frac{\varepsilon \delta}{8}$ sobre a escolha de $a, b \in[1, q-1]$.

Em outras palavras, o Lema 3.2 .2 nos diz que com uma probabilidade $\frac{\varepsilon \delta}{8}$, existe um oráculo com vantagem significativa e capaz de realizar as medidas-dx para a requisição de paridade do tipo $\operatorname{PAR}\left(\lambda, P K_{a}, P K_{b}\right)$.

Originalmente, os autores definem requisições com $\operatorname{PAR}\left(\lambda^{2}, P K_{a}, P K_{b}\right)$, uma vez que queremos o LSB de $\lambda^{2} x$. Isso obriga a construção de um oráculo que retira a raiz quadrada de $\lambda^{2}$. Entretanto, já seguindo a nossa solução simplificada de implementação, definimos a requisição como $\operatorname{PAR}\left(\lambda, P K_{a}, P K_{b}\right)$ e caberá ao oráculo elevar $\lambda$ ao quadrado antes de investigar o LSB de $\lambda^{2} x$.

A seguir, resumidamente apresentamos os passos do algoritmo BS:

1. com entrada $\left\langle E, G, P K_{a}, P K_{b}\right\rangle$, onde $P K_{a}=a G$ e $P K_{b}=b G$ e $G$ de ordem prima $q$, queremos calcular o ponto $C=a b G$;

2. como $a$ e $b$ são fixos (e desconhecidos), aleatorizamos o processo definindo $P K_{r a}=a_{r} a G$ e $P K_{r b}=b_{r} b G$, para $a_{r}, b_{r} \in[1, q-1]$, e esperamos que os valores $a_{r} a$ e $b_{r} b$ levem ao caso do Lema 3.2 .2 cuja probabilidade do oráculo $\mathcal{B}_{p}$ é mantida; 
3. sendo $D H_{E, G}\left(P K_{r a}, P K_{r b}\right)=D$, basta calcular $D$ para obtermos $C$, pois $C=c_{r} \cdot D$, onde $c_{r} \equiv\left(a_{r} b_{r}\right)^{-1} \bmod q$;

4. agora, executamos um algoritmo similar ao ACGS com o oráculo $\mathcal{B}_{p}$;

5. similarmente para garantir as condições iniciais do ACGS ( $a^{\prime} x$ e $b^{\prime} x$ pequenos e coprimos), devemos repetir todo o processo $\frac{8}{\varepsilon \delta}$ vezes a fim de assegurar que encontremos os valores $a_{r} a$ e $b_{r} b$ desejados pelo Lema 3.2 .2 .

Ao final do algoritmo BS, teremos uma lista de candidatos $C$ para o ponto $a b G$. Porém, ao contrário do ACGS, não temos condições de identificar automaticamente a alternativa correta, o que nos obriga a executar todas as alternativas e apenas ao final tentar identificar a resposta correta. A identificação é possível com um algoritmo devido a Shoup Sho97.

A seguir, um resumo do algoritmo de Shoup para uso com o BS:

1. primeiro executamos o BS com entrada $\langle E, G, a G, b G\rangle$ e obtemos uma lista de $k$ candidatos $C_{1}, \ldots, C_{k}$

2. depois escolhemos aleatórios $w, z \in[1, q-1]$ e executamos o BS com entrada $\langle E, G, w(a G)+$ $z G, b G\rangle$ obtendo uma segunda lista de $k$ pontos $C_{1}^{\prime}, \ldots, C_{k}^{\prime}$;

3. $\forall 1 \leq w \leq k$ e $\forall 1 \leq z \leq k$ nós testamos se $w C_{i}+z(b G)=C_{j}^{\prime}$;

4. a resposta desejada é o $C_{i}$ cujo par $\left(C_{i}, C_{j}^{\prime}\right)$ satisfaz a equação acima.

A referência [Sho97, Theo.7] detalha mais sobre o processo de escolha da resposta correta. É fácil verificar que $w C+z(b G)=w(a b G)+a b G=(w a+z) b G=D H_{E, G}(w(a G)+z G, b G)=C^{\prime}$.

Um problema percebido durante a implementação é que durante o algoritmo Shoup, as comparações são feitas entre candidatos que são pontos na curva $E$. Contudo, o algoritmo BS retorna apenas a coordenada $x$ dos candidatos. Existe um processo em que dada a coordenada $x$ do ponto $Q$ e o LSB da coordenada $y$ de $Q$ é possível reconstruir o ponto $Q$ utilizando a equação de definição da curva. Como o BS não dá o LSB de $y$, duplicamos as comparações de Shoup, uma supondo $\operatorname{LSB}(y)=0$ e outra supondo $\operatorname{LSB}(y)=1$.

Ainda, não sabemos se ao final do BKGCD o retorno $\left[a^{\prime} x\right]_{p}= \pm 1$ corresponde a $\left[a^{\prime} x\right]_{p}=1$ ou a $\left[a^{\prime} x\right]_{p}=p-1$, o que aumenta as comparações de Shoup novamente por um fator 2. Por fim, essas ambiguidades se repetem dentro do algoritmo de Shoup devido ao fato dele se utilizar de duas chamadas ao BS. Por fim, temos que efetuar o processo de comparação de Shoup 16 vezes ao todo.

Abriremos uma seção breve, a seguir, para discutir o algoritmo JV, também para o DHCE.

\subsubsection{Sobre o algoritmo JV para o DHCE em isogenias}

O trabalho de JV é uma extensão do trabalho de BS, expandindo esse resultado para funcionar também em curvas que são isógenas. 
O JV foi o nosso ponto de partida na investigação da segurança dos bits dos sistemas criptográficos. Infelizmente, o algoritmo BS tem execução muito lenta e a extensão de JV faria o algoritmo demorar mais ainda. Assim, a implementação de JV foi abandonada. Mas no Capítulo 4 de resultados nós apresentamos inferências de tempo baseadas na execução de BS.

Nessa seção vamos ver a contribuição de JV e definir o tempo de execução de seus algoritmos.

Como vimos, dada uma curva $E_{0}$, o algoritmo BS trabalha dentro de uma família de curvas $\phi_{\lambda}\left(E_{0}\right)_{\lambda \in \mathbb{F}_{p}^{*}}$ que são isomorfas entre si. Agora, suponhamos uma curva $E_{1}$ que seja isógena a $E_{0}$, o algoritmo BS não consegue tirar vantagem de seu oráculo $\mathcal{B}_{p}$ para resolver o DHCE dentro de $E_{1}$.

Com a solução de JV isso se torna possível. Quando é dada uma curva $E$ onde o oráculo $\mathcal{B}_{p}$ não tem vantagem, o JV aplica sucessivas transformações em $E$ até que ela caia dentro de uma família de isomorfismo favorável a $\mathcal{B}_{p}$. Essas transformações são computadas através de isogenias, com isso, JV define famílias de isogenias onde o DHCE é inversível com auxílio de oráculos. Os autores ainda provam que para uma fração, polinomial em $\lg p$, das curvas o método também é aplicável.

Vamos apresentar uma sinopse da ideia por trás do trabalho de JV. Os seguintes passos são executados:

1. constrói-se um grafo, regular e conexo, cujos vértices são curvas isógenas e as arestas são as isogenias entre as curvas;

2. seja $V$ o conjunto dos vértices do grafo, existe um subconjunto $S \subset V$, tal que nas curvas dentro de $S$ o algoritmo BS é aplicável;

3. a proporção $\frac{|S|}{|V|}$ é polinomial em $\lg p$;

4. então, dada uma curva inicial $E_{0}$, deseja-se calcular $D H_{E_{0}, G}(a G, b G)$, lembrando que $q$ é a ordem de $G$;

5. efetuamos um passeio aleatório $E_{0}, E_{1}, \ldots, E_{t}$ no grafo de comprimento $t$;

6. seja $\phi$ a composição das isogenias ao longo do caminho e $\hat{\phi}$ a correspondente isogenia dual;

7. seja $d$ o grau de $\phi$, então calcula-se $e=d^{-1} \bmod q$;

8. se ao final do passeio $E_{t} \in S$, então executa o BS com entrada $\left\langle E_{t}, \phi(G), \phi(a G), \phi(b G)\right\rangle$;

9. seja $Q \in E_{t}$ o ponto retornado por BS, então o algoritmo JV computa e retorna $e \hat{\phi}(Q) \in E_{0}$.

Sabemos que o ponto $e \hat{\phi}(Q)$ de fato está em $E_{0}$ devida a aritmética com isogenia dual discutida ao final da Seção 2.2 (pág. 10).

Para construir esse esquema, os autores se utilizaram de conceitos da Teoria Espectral dos Grafos. O grafo construído é chamado grafo de expansão. Um passeio aleatório dentro dele é capaz de levar qualquer vértice de entrada para dentro de um conjunto $S$ com probabilidade igual a $\frac{|S|}{2|V|}$. Para isso, o passeio deve ter comprimento pelo menos $t=\frac{\lg \left(\frac{2|V|}{|S|^{1 / 2}}\right)}{\lg \left(v^{-1}\right)}$, onde $0<v<1$ é chamado spectral gap [JV08, Prop.5.2] (deixamos à parte os detalhes sobre o valor de $v$ ). 
O que se vê aqui é que a existência de um algoritmo (o BS) para um problema no caso médio (qualquer $E \in S$ ) implica a existência de um algoritmo (o JV) para o pior caso $\left(E_{0} \notin S\right.$ ). Essa propriedade é chamada de random self-reducibility.

Como a probabilidade de $E_{t}$ cair em $S$ é igual a $\frac{|S|}{2|V|}$, devemos efetuar pelo menos $u=\frac{2|V|}{|S|}$ passeios para se garantir $E_{t} \in S$. Os autores escolhem por definição um tamanho de $|V|$ polinomial em $\lg p$, assim teremos $u=O(\lg p)$ e também $t=O(\lg p)$.

Por definição também, os autores escolhem isogenias que tenham grau $d=O\left((\lg p)^{2}\right)$. Como o cálculo de cada isogenia consome um tempo de $O\left(d^{4}\right)$ Koh96, o tempo de computação para cada $\phi$ é igual a $O\left((\lg p)^{8}\right)$.

Esse tempo, juntamente com os de $u$ e $t$, o tempo total de JV é $O\left((\lg p)^{10}\right)$ vezes o tempo de BS.

Haja vista que esse tempo é apenas para o caso mais simples do JV: isogenias de um único nível. Apenas mencionando, os autores definem as isogenias em três níveis que constituem os chamados vulcões de isogenias; o caso mais complexo é inverter o DHCE em múltiplos níveis de isogenias [JV08, Sec.6.3].

\subsection{Biblioteca criptográfica Relic}

Para implementar os algoritmo ACGS e BS, utilizamos a linguagem de programação C e a biblioteca criptográfica Relic Toolkit [AG]. A versão empregada foi a 0.3.0.

Seguindo a discussão na Seção 2.6 (pág. 17), utilizamos as curvas SECG_P160 e NIST_P192 da biblioteca para o DHCE. Para o RSA, utilizamos módulos de 1024, 2048 e 5000 bits, além de um módulo teórico de 128 bits para registrar tempos mais demorados.

A Relic já possui ferramentas de cronômetro (benchmark) para registrar os tempos de execução, nós utilizamos a versão mais precisa desses cronômetros (HPROC).

O gerador pseudoaleatório construído dentro da Relic é o FIPS 186-2 baseado em SHA1.

A respeito da implementação dos oráculos, a resposta para a consulta no DHCE é imediata, com a execução de apenas poucos cálculos. Já no RSA, é feita uma decriptação para cada consulta, resultando em um tempo para a resposta bem maior do que no caso anterior.

Os códigos fontes das implementações estão disponíveis no site do Laboratório de Segurança de Dados do IME-USP1 1 .

Nesse capítulo, apresentamos os inversores para os criptossistemas RSA e DHCE. Demos detalhes de implementação citando a biblioteca criptográfica Relic. A seguir, no Capítulo 4 de resultados vamos observar o desempenho dos métodos aqui descritos.

\footnotetext{
1 http://lsd.ime.usp.br/
} 


\section{Capítulo 4}

\section{Resultados}

Neste capítulo apresentamos os resultados obtidos das implementações. Temos três seções, na Seção 4.1 apresentamos os resultados para o RSA, na Seção 4.2 os resultados para o DHCE através de famílias de isomorfismo e na Seção 4.3 para o DHCE através de famílias isógenas.

Para simulação dos algoritmos e a coleta dos tempos de execução, nós utilizamos um computador com processador Intel Core 2 Duo T5450 de 1,66 Ghz com 2 GB de memória RAM. Rodamos os testes em apenas uma linha de execução (thread).

\subsection{Resultados para o algoritmo ACGS}

Apresentamos nessa seção os resultados para o RSA utilizando o algoritmo ACGS. Esse algoritmo foi descrito na Seção 3.1 (pág. 25).

Dividimos os resultados para o RSA em quatro seções: na Seção 4.1.1. temos uma explicação de como começamos os testes e os tempos do modelo original, na Seção 4.1.2, fazemos uma redução no número de amostras do algoritmo, na Seção 4.1.3, sugerimos ainda uma segunda forma de reduzir o tempo do algoritmo original (dentro da função BKGCD), e na Seção 4.1.4 mostramos quanto tempo seria dispendido para um ataque real ao RSA.

\subsubsection{Tempos do modelo original}

Pensamos inicialmente executar todo o algoritmo, mas os tempos de execução eram muito grandes, impossibilitando essa abordagem. Entretanto, dessa abordagem pudemos observar o seguinte fenômeno, não só na alternativa correta o algoritmo obtinha sucesso, mas também em algumas alternativas vizinhas. Ou seja, quando executamos em uma alternativa com os bits de $y$ e $z$ corretos, no intervalo $y$ correto e então se aproximando (ou afastando) do intervalo $z$ correto.

Apesar de ser interessante observar esse fenômeno, não há como dizer que seja um fato significativo, já que foram poucos os casos de sucesso frente a $2^{6} m \varepsilon^{-2}$ possibilidades. Por outro lado, 
ao rodar o algoritmo em alternativas que não a correta, nos proporcionou perceber um modo de diminuir o tempo do algoritmo pela metade. Vamos retornar a esse assunto na Seção 4.1.3 (pág. 45).

O sucesso da execução do algoritmo dependia que da escolha de $a$ e $b$, resultasse em $a x$ e $b x$ pequenos $\left(a b s_{N}(a x)<\frac{\varepsilon N}{2}\right)$, e além disso, que fossem primos entre si. Por agilidade e a fim de dar mais regularidade aos tempos apresentados, implementamos o algoritmo de modo a sempre garantir essas condições. Depois, para a inferência de tempos, adicionamos de volta o tempo médio necessário para satisfazê-las. Esse método é consistente, porque que as probabilidades envolvidas são bem conhecidas.

Então, tendo essas condições iniciais satisfeitas e rodando o algoritmo sempre na alternativa correta, calculamos os tempos do algoritmo ACGS. Entretanto, mesmo com esses cortes, rodar e observar o tempo do algoritmo para um RSA de 1024 bits ainda era muito demorado, ainda mais para vantagens pequenas, $\varepsilon<0,05$. Decidimos então coletar os dados de um RSA teórico de 128 bits para calcular esse tempo na alternativa correta.

Apresentamos a Figura 4.1 com os tempos para um RSA de 128 bits em relação ao número $m$ de amostras. Temos resultados com 16 até 1024 amostras, variando de 1 segundo até pouco mais de 1 minuto. Observe que de acordo com o tamanho das amostras, a cada vez que o tamanho da amostra dobra, o tempo consumido de processamento também dobra. Isso pode ser melhor observado na Figura 4.2, um gráfico de pontos ligados, dando um visual da linearidade amostras $\times$ tempo.

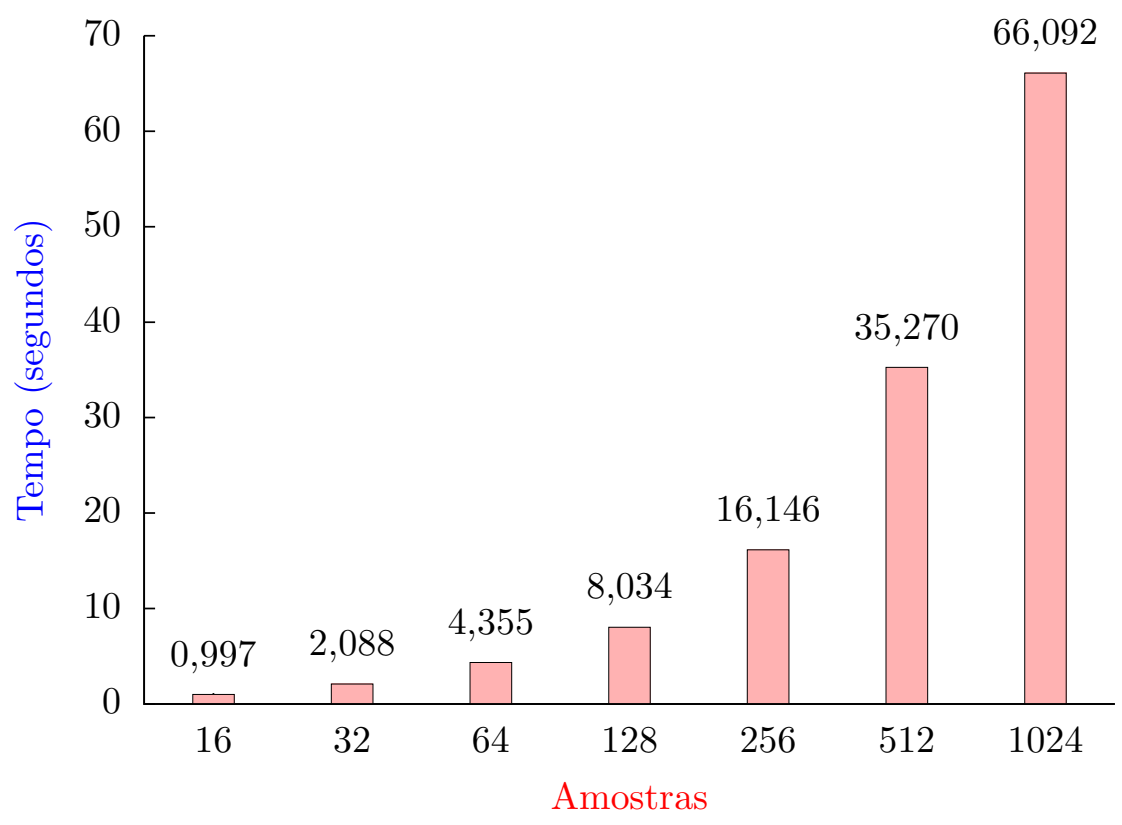

Figura 4.1: Tempo consumido em relação ao número de amostras.

Os tamanhos das amostras nas Figuras 4.1 e 4.2 foram propositalmente escolhidos para mostrar essa linearidade. A amostragem é feita dentro da função PAR e possui um número constante $m$. A função PAR por sua vez, é invocada dentro da função BKGCD, que faz um número variável de 


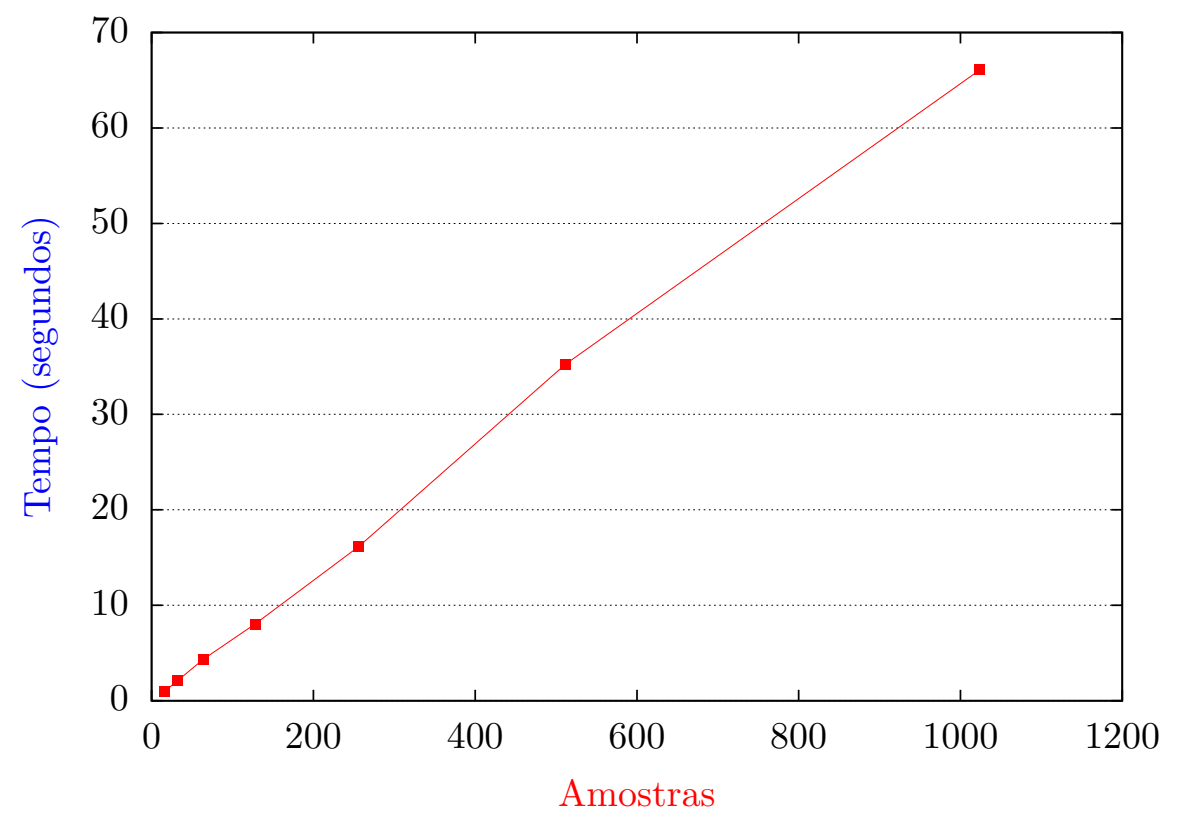

Figura 4.2: Linearidade do tempo consumido em relação ao número de amostras.

chamadas à função PAR. Apesar desse número ser variável, de acordo com os dados das figuras, ele não é muito discrepante a ponto de afetar a linearidade do gráfico. De fato, esse comportamento nos permite diminuir pela metade o tempo de execução do algoritmo, isso é discutido mais adiante na Seção 4.1 .3 (pág. 45).

Dessa discussão se verifica também que o tempo de execução se encontra majoritariamente dependente da amostragem. Sendo assim, o número de amostras $m$ é parâmetro crítico do sistema.

As operações aritméticas realizadas dentro do algoritmo têm tempo variável em relação ao número de bits dos números calculados. O tempo da exponenciação com números de 256 bits é maior do que com números de 128 bits, o tempo da exponenciação com números de 512 bits é maior do que com números de 256 bits, e assim por diante. Na Figura 4.3 temos o tempo gasto a cada chamada à função PAR em relação ao tamanho do operandos. Nesse teste, a função PAR faz 16 consultas ao oráculo. Note que o tempo para 5000 bits foi apenas indicado por uma flecha pelo fato de prejudicar as proporções do gráfico.

Como vimos, o parâmetro crítico do sistema é o número $m$ de amostragens. No modelo original do ACGS ele é por definição estabelecido conforme:

$$
m \stackrel{\text { def }}{=} \frac{64 n}{\varepsilon^{2}}
$$

Dessa forma, o valor de $m$ depende apenas do tamanho do módulo $N$ em bits e da vantagem $\varepsilon$ do oráculo. Na Tabela 4.1 apresentamos alguns exemplos de amostragem em relação ao par $n, \varepsilon$.

Assim, de acordo com a Tabela 4.1, para um RSA de 128 bits e um oráculo com vantagem 


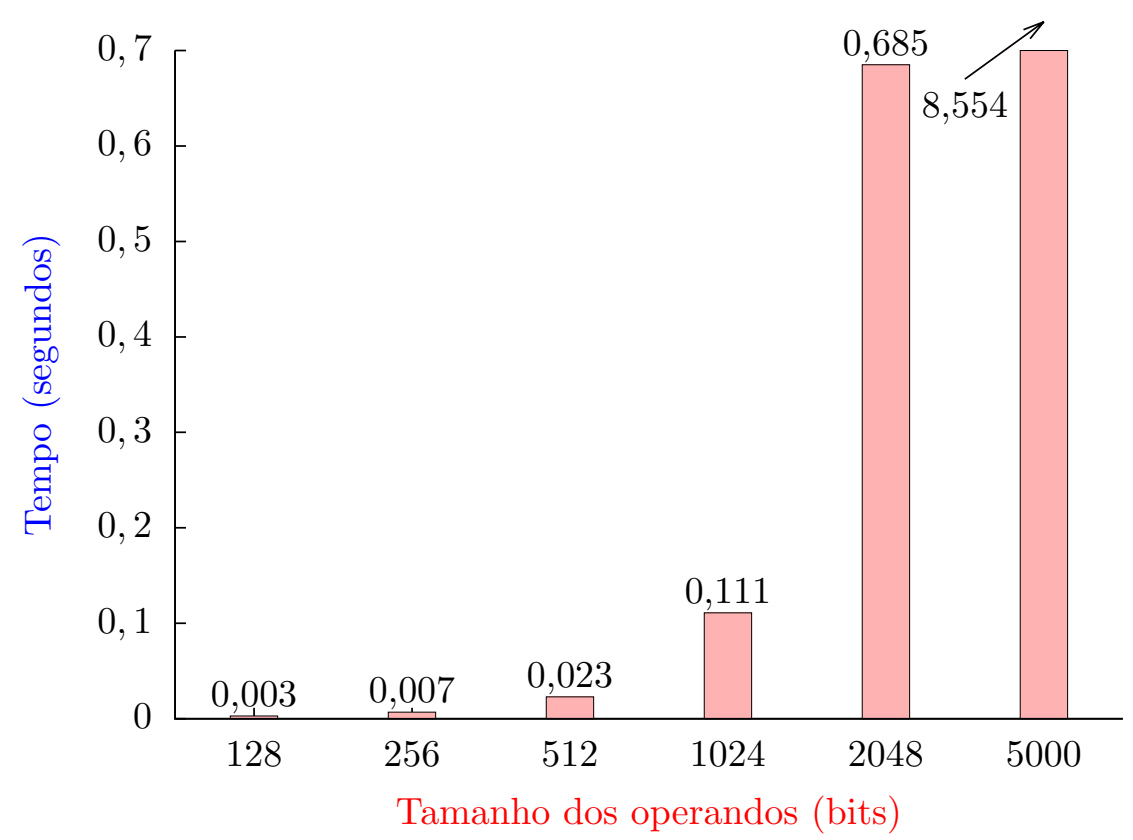

Figura 4.3: Tempo da função PAR no ACGS em relação aos bits dos operandos $(m=16)$.

\begin{tabular}{crrr} 
& 128 bits & 1024 bits & 5000 bits \\
\cline { 2 - 4 } 0,4 & 51.200 & 409.600 & 2.000 .000 \\
0,3 & 91.023 & 728.178 & 3.555 .556 \\
0,2 & 204.800 & 1.638 .400 & 8.000 .000 \\
0,1 & 819.200 & 6.553 .600 & 32.000 .000 \\
0,05 & 3.276 .800 & 26.214 .400 & 128.000 .000 \\
0,01 & 81.920 .000 & 655.360 .000 & 3.200 .000 .000 \\
\hline
\end{tabular}

Tabela 4.1: Amostragem em relação aos bits e à vantagem do oráculo.

de 40\%, temos um total de 51.200 amostras por chamada à função PAR. Com essa configuração, rodamos um teste e o tempo dispendido na função BKGCD foi de 3323, 433 segundos (55 minutos e 23 segundos). O que já é um tempo considerável, ainda mais em apenas um única alternativa. Um pequeno exercício nos leva a inferir o tempo para um oráculo com vantagem de 1\%, pela regra de três:

$$
\begin{aligned}
51.200 & \longrightarrow 3323,433 \text { segundos } \\
81.920 .000 & \longrightarrow x \text { segundos }
\end{aligned}
$$

Por essa equação levaríamos 5.317.492,8 segundos (perto de 61,5 dias) para efetuar o teste com $\varepsilon=0,01$, o que é impraticável para um simples teste com os recursos que dispomos.

Dessa forma, nem vamos tentar inferir o resultado para um RSA de 1024 bits. Concluímos que 
o ACGS no modelo original de amostragem, não poderia (com recursos computacionais modestos) explorar uma pequena vantagem no conhecimento do LSB da mensagem para um ataque de canal secundário em tempo razoável, nem mesmo para um RSA teórico de 128 bits.

\subsubsection{Diminuindo o número de amostras}

Procuramos então tentar reduzir o valor do parâmetro crítico do sistema, o número $m$ de amostras. Percebemos que para valores menores do que o do modelo original, o algoritmo ACGS ainda obtinha sucesso em alguns casos. Após várias tentativas, obtivemos, de maneira experimental, a seguinte definição do parâmetro:

$$
m \stackrel{\text { def }}{=} \frac{4}{\varepsilon^{2}}
$$

Como primeira observação, temos uma redução do fator constante 64 para 4 e agora, a quantidade de amostras não depende mais da tamanho do módulo do RSA. Compare a Equação (4.1) com a Equação (4.2). Todavia, como segunda observação, isso não significa que essa independência não afete o tempo de execução, uma vez que esse é influenciado pelo tamanho dos operandos, como ilustrado pela Figura 4.3 .

Vamos à explicação dessa definição da amostragem. Sabíamos que os erros eram superestimados. Ainda, na análise de erro da Seção 3.1 (pág. 25), a demonstração utiliza como ferramenta matemática a Desigualdade de Chebyshev, onde já suspeitávamos que poderia produzir um limitante não muito preciso para a probabilidade de erro (q.v. nossa discussão na Seção 2.10, pág. 23). Como resultado da demonstração, tínhamos o seguinte limitante na probabilidade de erro:

$$
\operatorname{Pr}(\mathrm{PAR} \text { errar })<\frac{4}{m \varepsilon^{2}}
$$

Substituindo a novo valor de amostragem nessa equação, obtemos:

$$
\operatorname{Pr}(\mathrm{PAR} \text { errar })<\frac{4}{\frac{4}{\varepsilon^{2}} \varepsilon^{2}}=1
$$

O que é muito curioso, já que no modelo original esse erro era limitado por $\frac{1}{16 n}$. Esse é um forte indício de que o limitante obtido através da Desigualdade de Chebyshev não é muito preciso.

Na Figura 4.4, apresentamos exemplos para o novo padrão de amostragem. Note que no gráfico incluímos apenas a vantagem do oráculo, já que nesse novo padrão o tamanho do módulo não influencia o número de amostras. Faça uma comparação com os valores da Tabela 4.1 .

Utilizando então essa nova metodologia, executamos simulações do ACGS para um RSA de 128 bits. O algoritmo obteve sucesso em sucessivas execuções até parar na primeira vez que falhou e não conseguiu recuperar a mensagem original. Observamos os seguintes resultados:

- $\varepsilon=0,4:$ rodou 66 vezes e parou; 


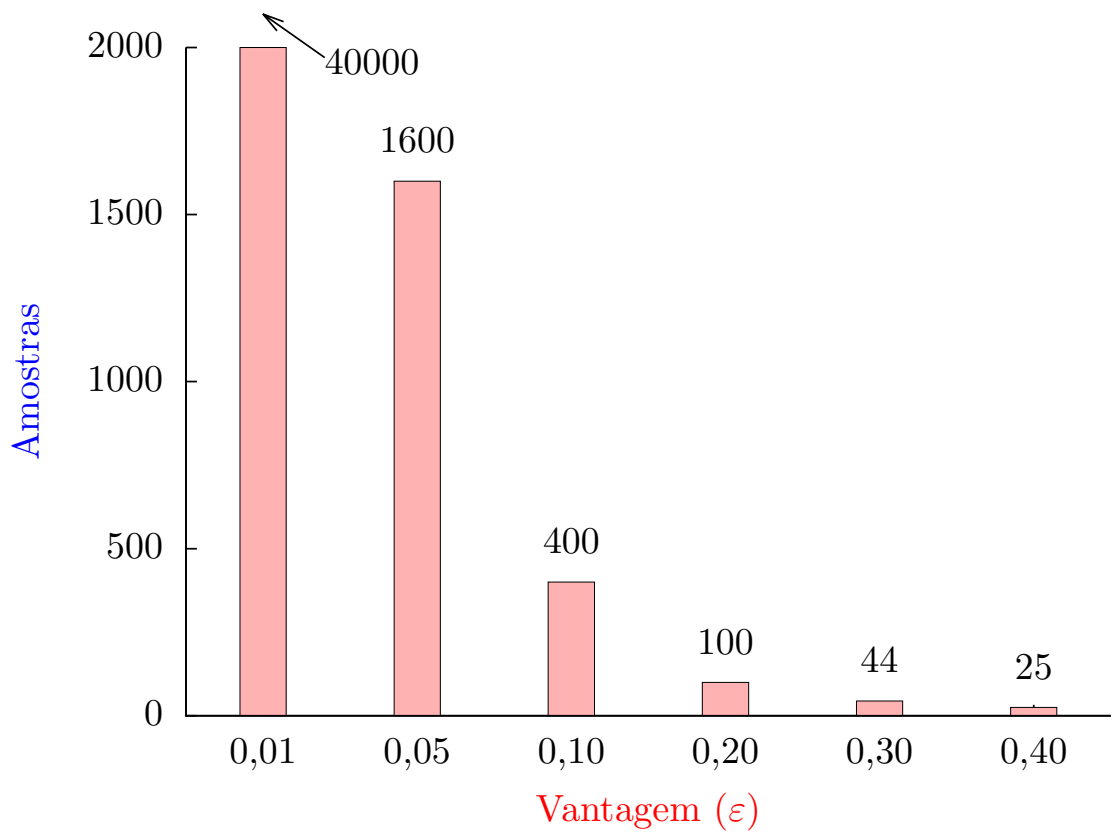

Figura 4.4: Número de amostras em relação à vantagem do oráculo.

- $\varepsilon=0,3:$ rodou 30 vezes e parou;

- $\varepsilon=0,2$ : falhava sempre;

- $\varepsilon=0,1:$ rodou 44 vezes e parou;

- $\varepsilon=0,05:$ rodou 4 vezes e parou;

- $\varepsilon=0,01$ : rodou 2 vezes e continuou.

Primeiro vamos observar o caso de $\varepsilon=0,01$. Ele rodou 2 vezes com sucesso, mas tivemos que abortar já que cada teste levou cerca de 40 minutos para ser executado, sendo que o algoritmo poderia continuar obtendo sucesso nas próximas execuções.

Tivemos problemas para $\varepsilon=0,2$ e $\varepsilon=0,05$, com $m=100$ e $m=1600$, respectivamente. Pareceu-nos que a quantidade de amostras definidas eram insuficientes para que o oráculo pudesse dar convergência à função PAR. Porém, com apenas a adição de uma unidade em cada um desses testes $(m=101$ e $m=1601)$, pudemos alterar o quadro anterior conforme:

- $\varepsilon=0,4$ : rodou 66 vezes e parou;

- $\varepsilon=0,3:$ rodou 30 vezes e parou;

- $\varepsilon=0,2$ : rodou 53 vezes e parou;

- $\varepsilon=0,1:$ rodou 44 vezes e parou; 
- $\varepsilon=0,05:$ rodou 29 vezes e parou;

- $\varepsilon=0,01:$ rodou 2 vezes e continuou.

Esses novos resultados, oferecem um segundo indício: a nova amostragem, tal como definida, se encontra muito perto do valor mínimo que se casaria perfeitamente com a distribuição de erro do ACGS — distribuição essa que desconhecemos.

Embora com o novo padrão de amostragem o ACGS passasse a falhar, isso em um ataque prático pode ser tolerado, já que se uma execução falhar, pode-se repetir a execução com a mesma entrada e obter sucesso. Ainda, a necessidade de repetições seria pequena tendo em vista a taxa de falhas dos resultados apresentados.

Na procura por um ACGS que não falhasse, dobramos a amostragem para $m \stackrel{\text { def }}{=} \frac{8}{\varepsilon^{2}}$. Com esse valor, rodando para as três menores vantagens - 40, 30 e 20\%, por serem mais rápidos - e o algoritmo nunca falhou (pelo menos nas 200 primeiras execuções, depois abortamos pela limitação de tempo).

\subsubsection{Redução no limitante do BKGCD}

Observamos um fato particular ao rodar o algoritmo completo - tanto na alternativa correta como em todas as outras. Nas alternativas incorretas onde o algoritmo falhava (como o esperado), o algoritmo abortava sempre pelo fato de se ultrapassar o limite máximo definido pelo BKGCD. Já na alternativa correta, a função BKGCD retornava antes de atingir esse limite e com números de passos mais ou menos próximos.

O objetivo do ACGS é inverter o RSA e isso deve ser garantido acontecer dentro da alternativa correta. Então, devemos ter o limitante do BKGCD direcionado primordialmente para essa alternativa. Para descobrir tal valor, rodamos o ACGS para um RSA de 128 bits apenas na alternativa correta. Dentro de 200 testes, a função BKGCD fez de 324 a 368 chamadas à função PAR, ou seja, algo entre $2,53 n$ e $2,88 n$. Não conseguimos observar uma execução na alternativa correta com mais de $3 n$ chamadas à função PAR.

Na Figura 4.5, temos o tempo gasto dentro da função BKGCD em relação ao tamanho do operandos. Incluímos os tempos para operandos de 128, 256, 512 e 1024 bits dentro de dois conjuntos de dados, um com 16 amostras e outro com 32 amostras. Mais uma vez, para privilegiar a estética do gráfico, foi omitida a barra do maior valor, o tempo para 1024 bits no conjunto de 32 amostras. Podemos comparar essa figura com a Figura 4.3 e inferir pelos tempos de execução que em nenhum dos casos ocorreu que a função BKGCD demorou mais do que $3 n$ chamadas à função PAR.

Como observação adicional, apesar de uma rápida análise da Figura 4.5]não permitir determinar facilmente o quão o tempo pode aumentar de acordo com uma adição no número de bits, ainda pode-se observar o fato de que ao dobrar o número de amostras dobra-se o tempo gasto.

O limitante da função BKGCD é definido por limite $G C D=6 n+3$, mas de acordo com nossas expectativas esse valor poderia ser alterado para limite $G C D=3 n$. Note que essa redução afeta não apenas a alternativa correta, mas também todas as demais alternativas, oferecendo uma redução pela metade no tempo do ACGS. 


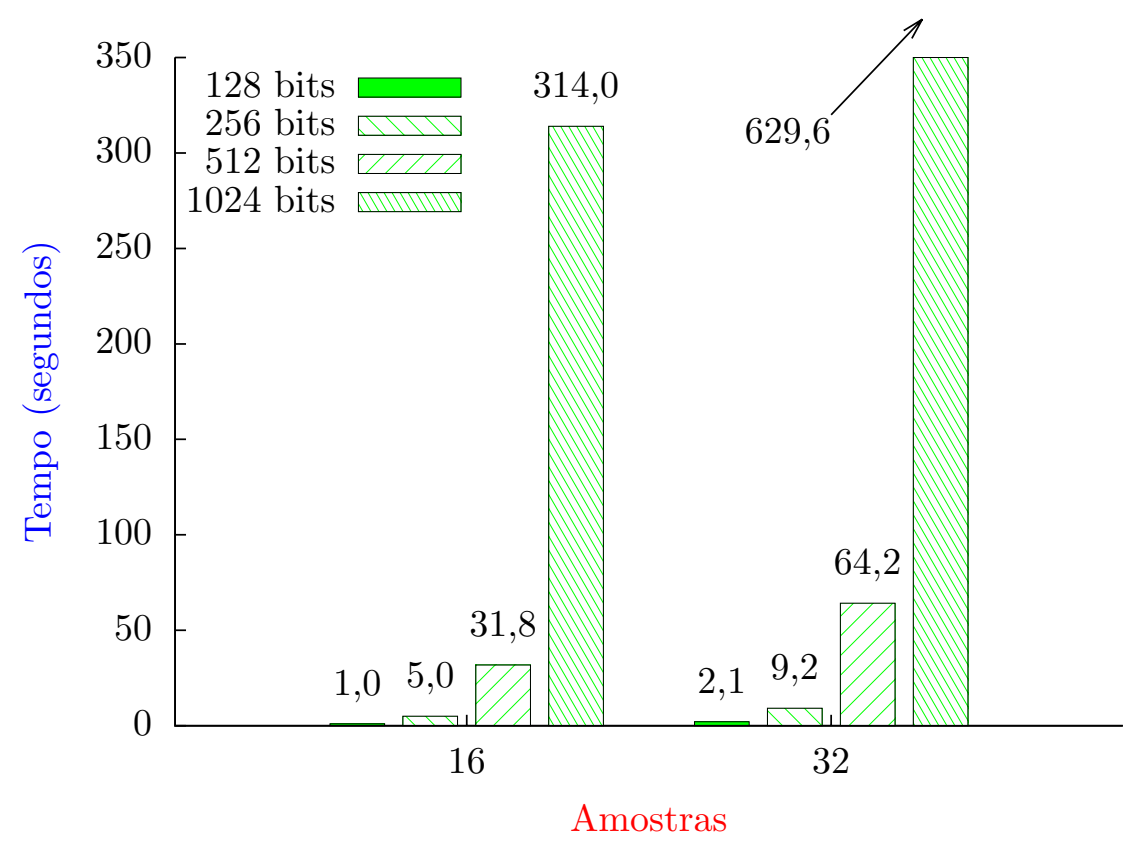

Figura 4.5: Tempo da função BKGCD em relação aos bits dos operandos.

Com a redução no limitante no BKGCD e com a redução no número de amostras podemos fazer inferências de tempo para o ACGS, veremos isso na Seção 4.1.4 a seguir.

\subsubsection{Inferência de tempos para o RSA}

Até agora, apresentamos tempos para um RSA teórico de 128 bits ignorando as condições iniciais e executando apenas na alternativa correta. Nessa seção, vamos inferir os tempos de um ACGS completo para valores de $n$ iguais a 1024, 2048 e 5000 bits. Vamos utilizar o novo padrão de amostragem e o limitante do BKGCD reduzido.

Como foi visto na Seção 3.1 (pág. 25), o tempo esperado para que $a x$ e $b x$ sejam pequenos era de $\varepsilon^{-2}$ e para que sejam coprimos era de 2. Além disso, o ACGS supõe o conhecimento prévio do LSB dos valores $r_{i} x$ calculados, bem como a localização aproximada desses, esses palpites somam $2^{6} m \varepsilon^{-2}$ possibilidades. Assim, esse é o trabalho adicional ao rodar um ACGS completo.

Para calcular os tempos, além do trabalho adicional, temos que considerar o tamanho do módulo $N$, porque mesmo que ele não influencie no número de amostragens, o tamanho dos operandos influenciam no tempo das operações e no número de passos dentro da função BKGCD. Vamos tomar o número máximo de iterações dentro da função BKGCD (3n) para calcular o tempo total do algoritmo, isso nos dará um limitante superior do tempo.

Assim, a fórmula geral inclui: os tempos da condição inicial $\left(\varepsilon^{-2} \cdot 2\right)$, o tempo de cada uma das alternativas $\left(2^{6} m \varepsilon^{-2}\right)$, o tempo da função $\operatorname{BKGCD~}(3 n)$, o tempo da função $\operatorname{PAR}(m)$ e o tempo 
do oráculo (1, consideramos constante):

$$
\begin{aligned}
\left(\varepsilon^{-2}\right)(2)\left(2^{6} m \varepsilon^{-2}\right)(3 n)(m)(1) & =3 \cdot 2^{7} \varepsilon^{-4} n m^{2} \\
& =3 \cdot 2^{7} \varepsilon^{-4} n\left(\frac{4}{\varepsilon^{2}}\right)^{2} \\
& =3 \cdot 2^{7} \varepsilon^{-4} n 2^{4} \varepsilon^{-4} \\
& =3 \cdot 2^{11} \varepsilon^{-8} n
\end{aligned}
$$

Construímos uma tabela para inserir essa nova estimativa da complexidade e fazer uma comparação entre as demais já conhecidas (Seção 3.1 3.1.1 pgs. 25 e 32 respectivamente). Adicionamos também o tempo do algoritmo de solução para o PFI ([BLP93]) como o utilizado em FS. Também como em FS, adotamos $\varepsilon=0,01$. O resultado se vê na Tabela 4.2.

\begin{tabular}{clrrr} 
& Estimativa & 1024 bits & 2048 bits & 5000 bits \\
\hline PFI & $\exp \left(1,9(\ln N)^{\frac{1}{3}}(\ln \ln N)^{\frac{2}{3}}\right)$ & $6,409 \cdot 10^{25}$ & $5,817 \cdot 10^{34}$ & $3,755 \cdot 10^{50}$ \\
ACGS orig. & $3 \cdot 2^{20} \varepsilon^{-8} n^{3}$ & $3,378 \cdot 10^{31}$ & $2,702 \cdot 10^{32}$ & $3,932 \cdot 10^{33}$ \\
ACGS novo & $3 \cdot 2^{11} \varepsilon^{-8} n$ & $6,292 \cdot 10^{22}$ & $1,258 \cdot 10^{23}$ & $3,072 \cdot 10^{23}$ \\
FS 1 & $3 \cdot 2^{9} \varepsilon^{-6} n^{2}$ & $1,611 \cdot 10^{21}$ & $6,443 \cdot 10^{21}$ & $3,840 \cdot 10^{22}$ \\
FS 2 & $9 \cdot 2^{8} \varepsilon^{-6} n \lg n$ & $2,359 \cdot 10^{19}$ & $5,191 \cdot 10^{19}$ & $1,498 \cdot 10^{20}$ \\
\hline
\end{tabular}

Tabela 4.2: Comparação entre as complexidades existentes.

Agora podemos utilizar os tempos da função PAR na Figura 4.3 para obter estimativas de tempo. Nessa figura, temos o uso de apenas 16 amostras, mas como vamos utilizar $\varepsilon=0,1$, teremos $m=400$. Assim, seja tPAR o tempo da função PAR na Figura 4.3, o cálculo proporcional se dá pela fórmula $\frac{400}{16} \mathrm{tPAR} \cdot 3 n \cdot 2^{6} m \varepsilon^{-2} \cdot \varepsilon^{-2} \cdot 2$, onde temos, respectivamente, a alteração do número de amostras, as chamadas pela função BKGCD, o número de alternativas e as condições iniciais:

$$
\begin{aligned}
\frac{400}{16} \mathrm{tPAR} \cdot 3 n \cdot 2^{6} m \varepsilon^{-2} \cdot \varepsilon^{-2} \cdot 2 & =25 \cdot \mathrm{tPAR} \cdot 3 n \cdot 2^{7} \cdot 400 \cdot \varepsilon^{-4} \\
& =3 \cdot 10^{4} \cdot \mathrm{tPAR} \cdot 2^{7} \cdot(0,1)^{-4} \cdot n \\
& =3 \cdot 10^{8} \cdot \mathrm{tPAR} \cdot 2^{7} \cdot n \\
& =3,84 \cdot 10^{10} \cdot \mathrm{tPAR} \cdot n
\end{aligned}
$$

Com o resultado da Equação (4.3) podemos montar a Tabela 4.3 dos tempos estimados para se tentar inverter o RSA. Temos uma coluna para o tempo na alternativa correta e uma coluna para o tempo total do algoritmo, além do tempo tPAR da Figura 4.3.

Nossos resultados resumidos na Tabela 4.3 são estimativas de tempos que consideramos muito grandes. Talvez as estimativas pudessem ser reduzidas com a obtenção de um oráculo realmente de tempo unitário (nosso oráculo efetua uma decriptação internamente), ou ainda, se ao usar o algoritmo FS tenhamos um ganho significativo em relação ao ACGS.

Terminamos aqui o estudo para o RSA. Na Seção 4.2, a seguir, faremos o estudo para o DHCE. 


\begin{tabular}{ccrr}
$\mathrm{n}$ (bits) & tPAR $(\mathrm{s})$ & Alt. correta & Tempo total \\
\hline 1024 & 0,111 & 19,7 dias & $138,4 \cdot 10^{3}$ anos \\
2048 & 0,685 & 243,5 dias & $1,7 \cdot 10^{6}$ anos \\
5000 & 8,554 & 20,3 anos & $52,1 \cdot 10^{6}$ anos \\
\hline
\end{tabular}

Tabela 4.3: Tempos estimados para execução do algoritmo ACGS.

\subsection{Resultados para o algoritmo BS}

Apresentamos nessa seção os resultados para o DHCE utilizando o algoritmo BS. Esse algoritmo foi descrito na Seção 3.2 (pág. 33).

Dividimos os resultados para o DHCE em duas seções: uma sem uso do oráculo $\mathcal{B}_{p}$ e a outra com o emprego desse.

\subsubsection{Tempos sem o uso do oráculo B}

Vamos seguir a mesma linha de discussão como o da Seção 4.1para o RSA: com a nova amostragem definida na Seção 4.1.2 e com o limitante para o BKGCD igual a $3 \lg p$ conforme a Seção 4.1.3.

Também, os tempos são tomados dentro da alternativa correta e com as condições iniciais satisfeitas. Apenas uma execução do algoritmo BS é considerada, assim, não entra aqui as execuções adicionais requeridas pelo algoritmo de Shoup.

Quanto à função BKGCD, não há problemas com o limitante igual a $3 \lg p$. Entretanto, quanto à amostragem, deve-se levar em conta que vamos utilizar dois algoritmos, o oráculo $\mathcal{O}_{p}$ e o oráculo $\mathcal{B}_{p}$. O oráculo $\mathcal{B}_{p}$ é regido pelo parâmetro $\delta$ que define a proporção de curvas onde o oráculo $\mathcal{O}_{p}$ possui vantagem $\varepsilon$. O caso ideal é quando $\delta=1$, o que define o oráculo $\mathcal{O}_{p}$ como aplicável a todas as curvas da família.

No caso onde $\delta=1$ temos um algoritmo BS semelhante ao ACGS. Com base nesse valor podemos obter os tempos da função PAR para operandos de 160 bits e 224 bits em um DHCE. A Figura 4.6 mostra esses tempos para um número de amostras igual a $m=40000$. Mesmo com um número de amostras grande $m=40000$ (e portanto $\varepsilon=0,01$ ), a figura possui tempos pequenos em relação ao RSA, isso é devido ao fato de curvas elípticas precisarem de bem menos bits que o RSA para alcançar o mesmo nível de segurança e também pela forma como o oráculo para o DHCE é construído, que permite a ele ser muito mais rápido do que o utilizado para o RSA.

Resolvemos dobrar o número de amostras conforme $m \stackrel{\text { def }}{=} \frac{8}{\varepsilon^{2}}$. Vimos na Seção 4.1.2 que dessa maneira o algoritmo erra com menos frequência. Tomamos essa decisão pelo fato de que quando não tínhamos dobrado a amostragem, o algoritmo BS errava muito rapidamente - por exemplo, após a oitava execução. A partir disso, executamos simulações do BS para um DHCE de 160 bits. O algoritmo obteve sucesso em sucessivas execuções até errar ou ser abortado pela extensão do tempo. Temos os seguintes resultados desses testes:

- $\varepsilon=0,4:$ rodou 368 vezes e parou; 


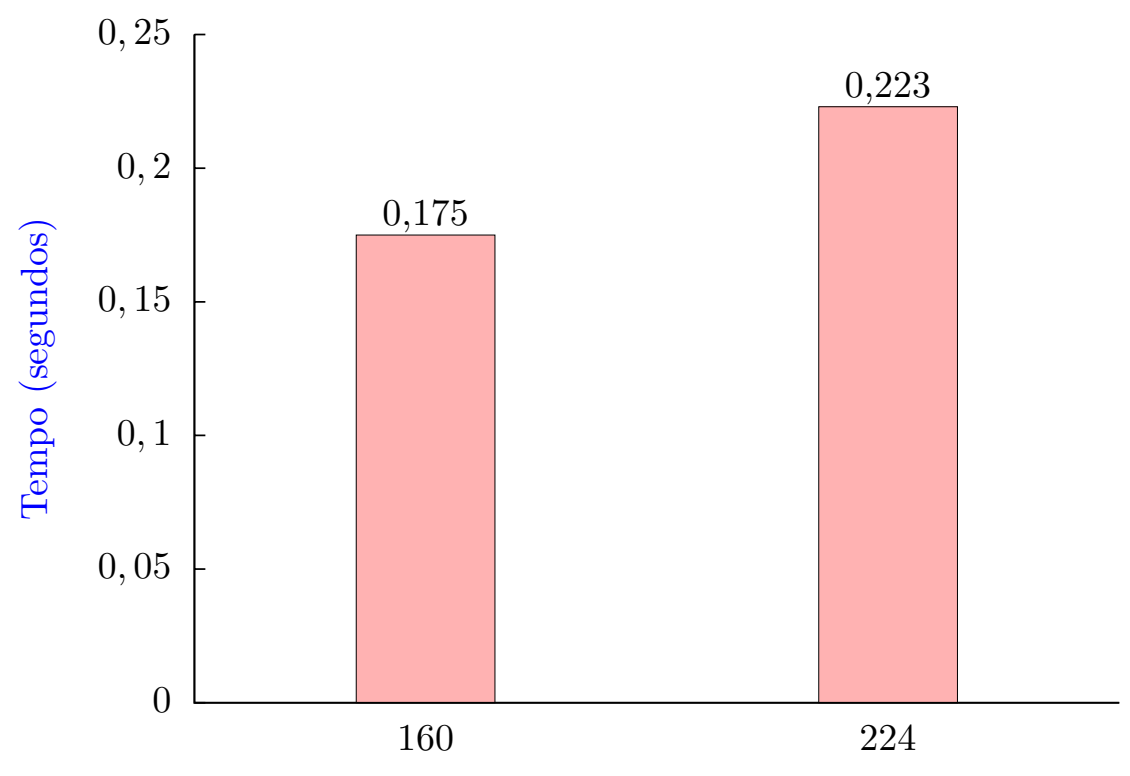

Tamanho dos operandos (bits)

Figura 4.6: Tempo da função PAR no DHCE em relação aos operandos $(m=40000)$.

- $\varepsilon=0,3:$ rodou 247 vezes e parou;

- $\varepsilon=0,2:$ rodou 183 vezes e parou;

- $\varepsilon=0,1:$ rodou 862 vezes e continuou;

- $\varepsilon=0,05$ : rodou 35 vezes e continuou;

- $\varepsilon=0,01$ : rodou 1 vez e continuou.

Agora vamos inferir os tempos para $\varepsilon=0,1$ e $m=800$. Com os tempos tPAR da Figura 4.6 e seguindo o cálculo da Equação (4.3), temos a fórmula para a alternativa correta:

$$
\begin{aligned}
\frac{800}{40000} \mathrm{tPAR} \cdot 3 \lg p \cdot \varepsilon^{-2} \cdot 2 & =\frac{1}{50} \cdot \mathrm{tPAR} \cdot 6 \lg p \cdot(0,1)^{-2} \\
& =12 \cdot \mathrm{tPAR} \cdot \lg p
\end{aligned}
$$

Seja nLinhas o número de alternativas possíveis, desenvolvendo, temos o tempo total:

$$
\begin{aligned}
\frac{800}{40000} \mathrm{tPAR} \cdot 3 \lg p \cdot n \text { Linhas } \cdot \varepsilon^{-2} \cdot 2 & =12 \cdot \mathrm{tPAR} \cdot \lg p \cdot n \text { Linhas } \\
& =12 \cdot \mathrm{tPAR} \cdot \lg p \cdot 2^{6} m \varepsilon^{-2} \\
& =768 \cdot \mathrm{tPAR} \cdot \lg p \cdot 800 \cdot(0,1)^{-2} \\
& =6,144 \cdot 10^{7} \cdot \mathrm{tPAR} \cdot \lg p
\end{aligned}
$$


Com as equações (4.4) e (4.5) podemos montar a Tabela 4.4 com os tempos estimados para se tentar descobrir a chave combinada pelo DHCE. Temos uma coluna para o tempo na alternativa correta e uma coluna para o tempo total do algoritmo, além do tempo tPAR da Figura 4.6.

\begin{tabular}{ccrr}
$\lg p$ (bits) & tPAR (s) & Alt. correta & Tempo total \\
\hline 160 & 0,175 & 5,6 minutos & 54,6 anos \\
224 & 0,223 & 9,9 minutos & 97,3 anos \\
\hline
\end{tabular}

Tabela 4.4: Tempos estimados para execução do algoritmo BS.

Comparando a Tabela 4.4 com a Tabela 4.3, podemos observar uma acentuada diminuição nos tempos quando consideramos sistemas com níveis de segurança equivalentes. Na Seção 4.2.2 a seguir, vamos abordar o caso $\operatorname{com} \delta<1$.

\subsubsection{Tempos usando o oráculo B}

Nesta seção, vamos abordar o caso oposto ao ideal, onde $\delta<1$ e próximo de zero. Isso significa que o oráculo $\mathcal{O}_{p}$ tem vantagem apenas em uma pequena fração das curvas dentro da família de isomorfismo. Fixamos $\delta=0,1$, de modo que em apenas $10 \%$ dos casos o oráculo $\mathcal{O}_{p}$ tem vantagem.

Executar os testes para essa seção foi muito difícil, pois os tempos de cada teste eram muito elevados. Vamos apresentar apenas um procedimento que executamos para obter uma simulação do algoritmo BS com uso do oráculo $\mathcal{B}_{p}$. Mesmo assim, o resultado que obtivemos é para um valor de vantagem muito alto, $\varepsilon=0,4(m=50)$.

Primeiro mantivemos a amostragem dobrada para a função PAR, $m \stackrel{\text { def }}{=} \frac{8}{\varepsilon^{2}}$. Depois executamos várias simulações modificando a amostragem do oráculo $\mathcal{B}_{p}$, vamos chamar essa amostragem de $m 2$. O intuito desse esforço é encontrar uma definição menor que a original $\left(\frac{4}{\varepsilon \delta}\right)^{3}$, baseado em argumentos como os da Seção 4.1.2. Por fim, fixamos essa amostragem como $m 2 \stackrel{\text { def }}{=} \frac{8}{\varepsilon \delta^{2}}$.

Vamos mostrar como a amostragem $m 2$ definitiva foi conseguida. Fixamos $\varepsilon=0,4$ e inicialmente definindo $m 2 \stackrel{\text { def }}{=} \frac{4}{\varepsilon \delta}$, procedemos da seguinte forma: definimos $\delta=0,9$ e o BS passou; definimos $\delta=0,5$ e o BS passou; definimos $\delta=0,4$ e o BS não passou; então mantivemos $\delta=0,4$ e dobramos $m 2$, assim o BS passou; definimos $\delta=0,3$ e o BS não passou.

Da metodologia acima, percebemos que conforme $\delta$ decrescia, o erro aumentava rapidamente, não bastando simplesmente multiplicar por um fator constante a amostragem $m 2$. Quando definimos $m 2 \stackrel{\text { def }}{=} \frac{8}{\varepsilon \delta^{2}}$ não tivemos mais problemas conforme $\delta$ diminuía — executamos até $\delta=0,1$.

Infelizmente, não podemos dar tanta certeza sobre a amostragem $m 2$. Isso porque devido ao tempo elevado da execução, só se observou o sucesso da execução do algoritmo BS para uma única execução. Se isso por um lado é um ponto negativo, devemos lembrar que caso falhe, o algoritmo BS pode ser repetido até $\frac{8}{\varepsilon \delta}$ vezes, conforme sua definição na Seção 3.2 (pág. [33). Isso abre espaço para considerar que $m 2$ pode ser menor do que da maneira que definimos, já que mesmo que o BS não execute com sucesso na primeira vez, ele pode alcançar êxito em algumas das próximas $\frac{8}{\varepsilon \delta}-1$ tentativas. 
Para inferir os tempos do BS utilizamos a Figura 4.7 que mostra os tempos de uma função PAR com $m=50$ e $m 2=10$. Podemos comparar essa figura com a Figura 4.6 que não usa o oráculo $\mathcal{B}_{p}$. À primeira vista, pode parecer que para conseguir os tempos da Figura 4.7 bastaria multiplicar os tempos da Figura 4.6 por $m 2$ e ajustar proporcionalmente o tamanho $m$. Contudo, devido a computações extras ao adicionar o oráculo $\mathcal{B}_{p}$, esse tempo é maior e a um fator aproximadamente igual a 183 para 160 bits (294 para 224 bits).

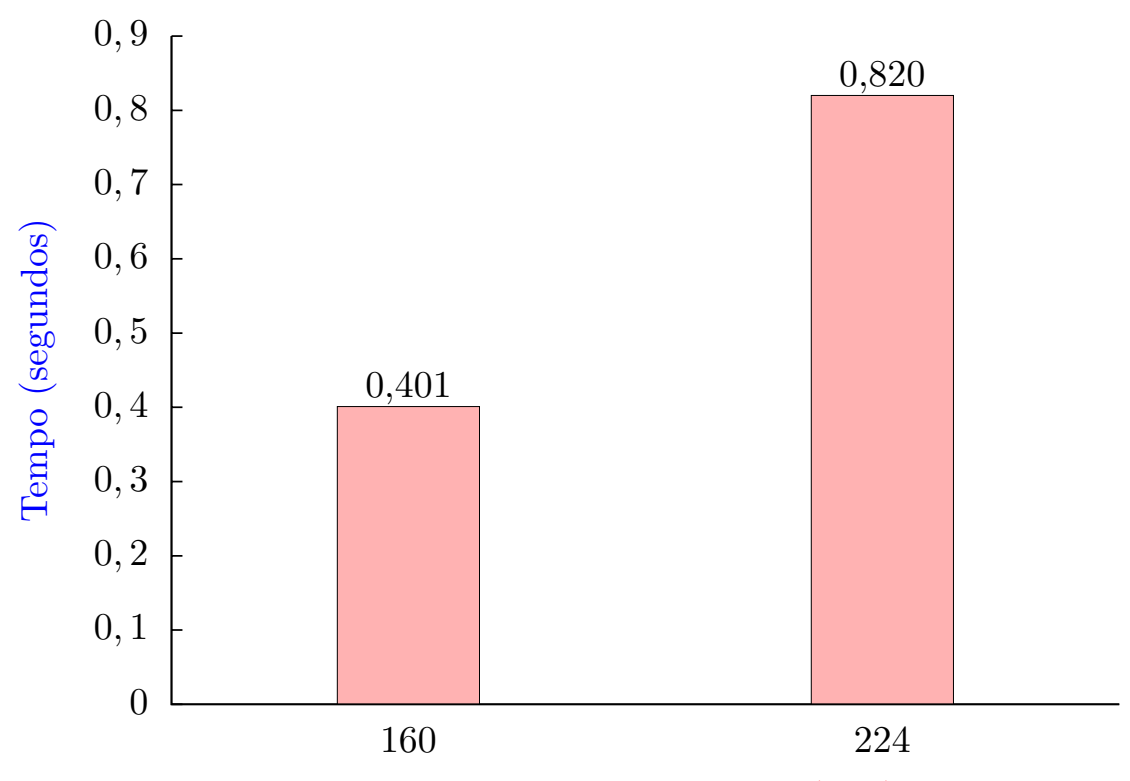

Tamanho dos operandos (bits)

Figura 4.7: Tempo da função PAR no DHCE com o oráculo $\mathcal{B}_{p}(m=50$ e $m 2=10)$.

Seguindo as equações (4.4) e (4.5), vamos inferir os tempos para $\varepsilon=0,1(\mathrm{~m}=800)$ e $\delta=0,1$ $(m 2=8000)$. Com os tempos tPAR da Figura 4.7, temos a fórmula para a alternativa correta:

$$
\begin{aligned}
\frac{800}{50} \cdot \frac{8000}{10} \cdot \operatorname{tPAR} \cdot 3 \lg p \cdot \varepsilon^{-2} \cdot 2 & =12800 \cdot \mathrm{tPAR} \cdot 6 \lg p \cdot(0,1)^{-2} \\
& =7,68 \cdot 10^{6} \cdot \mathrm{tPAR} \cdot \lg p
\end{aligned}
$$

Seja nLinhas o número de alternativas possíveis, desenvolvendo, temos o tempo total:

$$
\begin{aligned}
\frac{800}{50} \cdot \frac{8000}{10} \cdot \operatorname{tPAR} \cdot 3 \lg p \cdot n \text { Linhas } \cdot \varepsilon^{-2} \cdot 2 & =7,68 \cdot 10^{6} \cdot \mathrm{tPAR} \cdot \lg p \cdot \text { LLinhas } \\
& =7,68 \cdot 10^{6} \cdot \mathrm{tPAR} \cdot \lg p \cdot 2^{6} m \varepsilon^{-2} \\
& =4,915 \cdot 10^{8} \cdot \mathrm{tPAR} \cdot \lg p \cdot 800 \cdot(0,1)^{-2} \\
& =3,932 \cdot 10^{13} \cdot \mathrm{tPAR} \cdot \lg p
\end{aligned}
$$

Com as equações (4.6) e (4.7) podemos montar a Tabela 4.5 com os tempos estimados para se 
tentar descobrir a chave combinada pelo DHCE com uso do oráculo $\mathcal{B}_{p}$. Temos uma coluna para o tempo na alternativa correta e uma coluna para o tempo total do algoritmo, além do tempo tPAR da Figura 4.7

\begin{tabular}{ccrr}
$\lg p$ (bits) & tPAR $(\mathrm{s})$ & Alt. correta & Tempo total \\
\hline 160 & 0,401 & 15,6 anos & $80 \cdot 10^{6}$ anos \\
224 & 0,820 & 44,7 anos & $229 \cdot 10^{6}$ anos \\
\hline
\end{tabular}

Tabela 4.5: Tempos estimados para execução do algoritmo BS usando o oráculo $\mathcal{B}_{p}$.

Os tempos da Tabela 4.5 voltam a ser grandes como os da Tabela 4.3, devido ao fato de termos $\delta<1$. Na Seção 4.3 a seguir, faremos uma pequena inferência de tempos para o DHCE considerando isogenias.

\subsection{Tempos para o algoritmo JV}

Seguindo a Tabela 4.5, vamos inferir os tempos para $\varepsilon=0,1(m=800)$ e $\delta=0,1(m 2=8000)$ em um DHCE dentro de curvas isógenas, conforme discutido na Seção 3.2.1 (pág. 35).

Lembrando que levar uma curva $E_{0}$, onde o BS não consegue calcular a chave do DHCE, para uma curva $E_{t}$ (onde BS tem êxito) consome um tempo igual a um fator $O\left((\lg p)^{10}\right)$ maior que o tempo de BS. Assim, as estimativas de tempo do DHCE em isogenias são elevadas por esse fator. Consequentemente geramos a Tabela 4.6 .

\begin{tabular}{ccr}
$\lg p$ (bits) & tPAR $(\mathrm{s})$ & Tempo total \\
\hline 160 & 0,401 & $8,8 \cdot 10^{29}$ anos \\
224 & 0,820 & $7,3 \cdot 10^{31}$ anos \\
\hline
\end{tabular}

Tabela 4.6: Tempos estimados para execução do algoritmo JV usando o oráculo $\mathcal{B}_{p}$.

Os tempos da Tabela 4.6 são realmente grandes, ainda mais se pensarmos que estamos considerando o caso simplificado com apenas um nível de isogenia. Terminamos aqui nosso estudo para o DHCE.

Com os resultados exibidos nesse capítulo vimos uma redução no tempo do ACGS com nossa nova amostragem. Aplicando similar abordagem ao BS conseguimos manter a redução do tempo. Estimamos tempos de execução para o JV. Resumindo os resultados, fazemos nossas considerações finais a respeito desta dissertação no Capítulo 5 de conclusões a seguir. 


\section{Capítulo 5}

\section{Conclusões}

Com base nos algoritmos propostos, conseguimos construir implementações dos artigos com êxito na recuperação dos segredos. Alcançamos sucesso com um nível de convergência bem maior que o esperado. Nas implementações, fizemos o uso dos números pseudoaleatórios gerados pela Relic.

Nossos testes conseguiram, de maneira experimental, ajustar os parâmetros críticos do sistema para diminuir significativamente o tempo de execução. E com os tempos diminuídos, os métodos ainda alcançavam taxas de sucesso consideradas aceitáveis. O método experimental é aceitável devido a taxa de sucesso convergir para o valor esperado da probabilidade de sucesso dos métodos, a medida que se aumenta o número de execuções. Isto é garantido pela lei dos grandes números.

Sendo possível a convergência para o valor esperado, também é possível calcular a distribuição de probabilidade de sucesso dos métodos. Se conhecêssemos a distribuição, então poderíamos ajustar de maneira ótima os parâmetros críticos do sistema. Porém, essa metodologia é descartada pelo fato do tempo de execução dos algoritmos ser grande demais para se efetuar muitas repetições, principalmente para oráculos com vantagem pequena. Esse argumento justifica o método experimental.

Felizmente, os métodos implementados se mostraram bastante demorados, mesmo para uma vantagem de oráculo igual a 10\%, o que nós já consideramos grande. Isso mostra que as recomendações para tamanho de chaves do NIST conseguem privar nossos métodos de serem utilizados na prática - com os recursos computacionais modestos citados.

Na Seção 4.2.1 (pág. 48) entretanto, os tempos diminuíram bastante de maneira a viabilizar um ataque de canal secundário. Fizemos a suposição da existência de um oráculo que funcionasse para todas as curvas da família isomorfa. Isso é um risco potencial. Nossos algoritmos são facilmente paralelizáveis, pois as consultas ao oráculo são independentes e cada uma das alternativas também são independentes, podendo todos serem efetuados em linhas de execução diferentes. Hoje temos processadores com o dobro da frequência de operação de nossa plataforma de teste e com 6 núcleos (12 threads com tecnologia Hyper Threading ), assim, com apenas 5 desses processadores, temos um tempo de execução de 97,3 anos reduzido para menos de um ano.

Acabamos implementando o algoritmo ACGS em vez do FS pela cronologia do nosso trabalho. Por outro lado, o FS já era mais rápido que o PFI, e trabalhando com o ACGS tivemos a oportunidade de observar um algoritmo teórico ter seu patamar de tempo de execução diminuído ao ser 
trazido para prática.

Sugestões para trabalhos futuros. Ficamos curiosos em relação ao algoritmo FS, por sua terceira versão ser bem rápida e ainda também por utilizar Desigualdade de Chebyshev. Como trabalho futuro, uma implementação do FS poderia ser utilizada para diminuir ainda mais os tempos alcançados nesse trabalho. Nos algoritmos ACGS e FS existem versões para o Rabin que poderiam ser implementadas. Para verificar a viabilidade de uso em um ataque de canal secundário, seria muito interessante montar uma prova de conceito para nossos métodos. Poderia se criar uma implementação falha do RSA e então adaptá-la como oráculo para o FS. 


\section{Referências}

[ACGS88] Werner Alexi, Benny Chor, Oded Goldreich e Claus-Peter Schnorr. RSA and Rabin functions: Certain parts are as hard as the whole. SIAM Journal on Computing, 17(2):194209, Abril 1988.

[AG] D. F. Aranha e C. P. L. Gouvêa. RELIC is an Efficient LIbrary for Cryptography. http://code.google.com/p/relic-toolkit/.

[BBS86] Blum, Blum e Shub. A simple unpredictable pseudo-random number generator. SICOMP: SIAM Journal on Computing, 15, 1986.

[BK84] Brent e Kung. Systolic VLSI arrays for polynomial GCD computation. IEEE Transactions on Computers, 33, 1984.

[BLP93] J. P. Buhler, H. W. Lenstra e C. Pomerance. Factoring integers with the number field sieve. Em A. K. Lenstra e H. W. Lenstra, editores, The development of the number field sieve, volume 1554 de LNM, páginas 50-94. Springer-Verlag, Berlin, 1993.

[BM84] Manuel Blum e Silvio Micali. How to generate cryptographically strong sequence of pseudo-random bits. SIAM Journal on Computing, 13:850-864, 1984.

[BOCS83] M. Ben-Or, B. Chor e A. Shamir. On the cryptographic security of single RSA bits. Em ACM Symposium on Theory of Computing (STOC '83), páginas 421-430, Baltimore, USA, Abril 1983. ACM Press.

[BS01] Dan Boneh e Igor Shparlinski. On the unpredictability of bits of the elliptic curve DiffieHellman scheme. Em Joe Kilian, editor, CRYPTO 2001, volume 2139 de LNCS, páginas 201-212. Springer, 2001.

[BV96] Dan Boneh e Ramarathnam Venkatesan. Hardness of computing the most significant bits of secret keys in Diffie-Hellman and related schemes. Em Neal Koblitz, editor, CRYPTO '96, volume 1109 de LNCS, páginas 129-142. International Association for Cryptologic Research, Springer-Verlag, Berlin Germany, 1996.

[CFPZ09] Céline Chevalier, Pierre-Alain Fouque, David Pointcheval e Sébastien Zimmer. Optimal randomness extraction from a Diffie-Hellman element. Em Antoine Joux, editor, EUROCRYPT 2009, volume 5479 de LNCS, páginas 572-589. Springer-Verlag, 2009. 
[Cho86] Ben-Zion Chor. Two Issues in Public Key Cryptography. MIT Press, Cambridge MAN, USA, 1986.

[DH76] Whitfield Diffie e Martin Hellman. New directions in cryptography. IEEE Transactions on Information Theory, 22(6):644-654, Novembro 1976.

[Fra03] John B. Fraleigh. A First Course in Abstract Algebra. Addison-Wesley, 7a. edição, 2003.

[FS97] Roger Fischlin e Claus-Peter Schnorr. Stronger security proofs for RSA and Rabin bits. Em EUROCRYPT '9\%, volume 1233 de LNCS, páginas 267-279, Berlin, 1997. SpringerVerlag.

[FS00] Roger Fischlin e Claus-Peter Schnorr. Stronger security proofs for RSA and Rabin bits. Journal of Cryptology, 13(2):221-244, 2000.

[GMT82] Shafi Goldwasser, Silvio Micali e Po Tong. Why and how to establish a private code on a public network (extended abstract). Em FOCS, páginas 134-144, Chicago, Illinois, Novembro 1982. IEEE.

[HK09] Dennis Hofheinz e Eike Kiltz. Practical chosen ciphertext secure encryption from factoring. Em Antoine Joux, editor, EUROCRYPT 2009, volume 5479 de LNCS, páginas 313-332. Springer, 2009.

[JV08] Dimitar Jetchev e Ramarathnam Venkatesan. Bits security of the elliptic curve DiffieHellman secret keys. Em David Wagner, editor, CRYPTO 2008, volume 5157 de LNCS, páginas 75-92. Springer, 2008.

[Knu81] Donald E. Knuth. The Art of Computer Programming, volume 2, Seminumerical Algorithms. Addison-Wesley, Reading, MA, 2a. edição, 1981.

[Kob87] Neal Koblitz. Elliptic curve cryptosystems. Mathematics of Computation, 48(177):203209, 1987.

[Koh96] David Kohel. Endomorphism rings of elliptic curves over finite fields. Tese de Doutorado, University of California at Berkeley, 1996.

[Len87] H. W. Lenstra, Jr. Factoring integers with elliptic curves. Annals of Mathematics, 126:649-673, 1987.

[Mil86] Victor S. Miller. Use of elliptic curves in cryptography. Em Hugh C. Williams, editor, CRYPTO 1985, volume 218 de LNCS, páginas 417-426. Springer-Verlag, 1986.

[MS90] Silvio Micali e Claus-Peter Schnorr. Efficient, perfect random number generators. Em S. Goldwasser, editor, CRYPTO '88, volume 403 de LNCS, páginas 173-198. SpringerVerlag, 1990.

[MS91] Silvio Micali e Claus-Peter Schnorr. Efficient, perfect polynomial random number generators. Journal of Cryptology, 3(3):157-172, 1991. 
[MVO96] Alfred J. Menezes, Scott A. Vanstone e Paul C. Van Oorschot. Handbook of Applied Cryptography. CRC Press, Boca Raton, FL, USA, 1996.

[NIS11] NIST. SP800-57: Recommendation for key management - part 1: general, rev. 3. Relatório técnico, National Institute of Standards and Technology, Maio 2011.

[Rab79] M. Rabin. Digitalized signatures as intractable as factorization. Relatório Técnico MIT/LCS/TR-212, MIT Laboratory for Computer Science, Janeiro 1979.

[RH10] Dongyoung Roh e Sang Geun Hahn. On the bit security of the weak Diffie-Hellman problem. Information Processing Letters, 110:799-802, Setembro 2010.

[Ros06] Sheldon M. Ross. A First Course in Probability. Prentice Hall, New Jersey, 7a. edição, 2006 .

[RSA78] Ronald L. Rivest, Adi Shamir e Leonard M. Adleman. A method for obtaining digital signatures and public key cryptosystems. Communications of the ACM, 21(2):120-126, Fevereiro 1978.

[Sho97] Victor Shoup. Lower bounds for discrete logarithms and related problems. Em Walter Fumy, editor, EUROCRYPT '97, volume 1233 de LNCS, páginas 256-266, Berlin Germany, 1997. Springer-Verlag.

[Sil86] Joseph H. Silverman. The arithmetic of elliptic curves, volume 106 de Graduate texts in Mathematics. Springer, 1986.

[Ste67] J. Stein. Computational problems associated with Racah algebra. Journal of Computational Physics, 1(3):397 - 405, 1967.

[Ter08] Routo Terada. Segurança de Dados. Editora Blucher, São Paulo, 2a. edição, 2008.

[VV83] Umesh V. Vazirani e Vijay V. Vazirani. RSA bits are $.732+\epsilon$ secure (preliminary abstract). Em David Chaum, editor, CRYPTO '83, páginas 369-375. Plenum Press, 22-24 Agosto 1983.

[Was08] Lawrence C. Washington. Elliptic curves: number theory and cryptography. Discrete mathematics and its applications. Chapman and Hall/CRC, 2a. edição, 2008. 